THE INTERPLAY OF LEGITIMACY GAINS AND TECHNICAL GAINS IN THE

ADOPTION OF SOCIAL MEDIA

A Dissertation presented to the Faculty of the Graduate School

University of Missouri

In Partial Fulfillment

Of the Requirement for the Degree

Doctor of Philosophy

by

BRENT B. CLARK

Dr. Karen A. Schnatterly, Dissertation Advisor

MAY 2013 
The undersigned, appointed by the Dean of the Graduate School, have examined the dissertation entitled

\section{THE INTERPLAY OF LEGITIMACY GAINS AND TECHNICAL GAINS IN THE ADOPTION OF SOCIAL MEDIA}

Presented by Brent B. Clark

A candidate for the degree of Doctor of Philosophy of Business Administration

And hereby certify that in their opinion it is worthy of acceptance.

Dr. Karen Schnatterly

Dr. John Howe

Dr. Lin Jiang

Dr. Richard Johnson 
This dissertation is dedicated to my wife Missy. Not only is she my best friend, but I couldn't have accomplished all that I have without her. 


\section{ACKNOWLEDGEMENTS}

I want to thank the members of my dissertation committee, Rick Johnson, Lin Jiang, and John Howe. I am sincerely grateful to them for taking the time to encourage and support me throughout the dissertation process.

I especially want to express my gratitude to my dissertation advisor, Karen Schnatterly. Her advice has been wise. Her support has been encouraging. Her feedback has been developmental. Her friendship has been invaluable.

I also want to thank my fellow doctoral students. Their friendship and encouragement has been a key part of making these last four years so enjoyable and worthwhile. 
ACKNOWLEDGEMENTS ................................................................................ ii

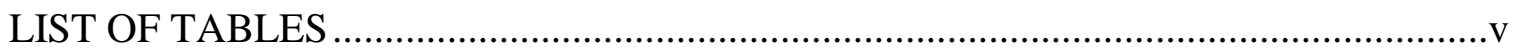

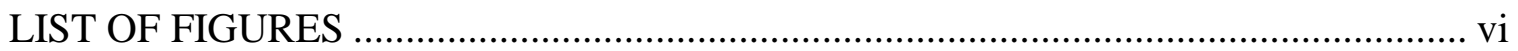

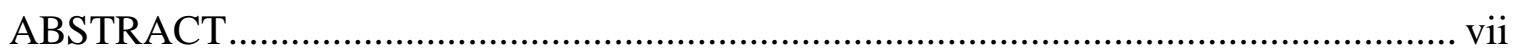

\section{Chapter}

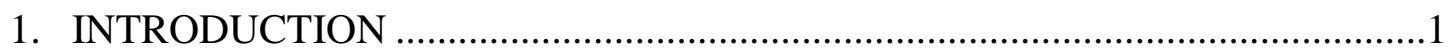

2. LITERATURE REVIEW: INSTITUTIONAL THEORY ...................................

Foundations of Institutional Theory

Recent Developments in Institutional Theory

3. THEORY AND HYPOTHESIS DEVELOPMENT

Isomorphic Adoption and its Benefits

The Difficulty of Separating Legitimacy and Technical Performance Gains

The Timing Implications of Technical and Legitimacy Gains

What Are Technical Gains and Where Do They Come From?

What Are Legitimacy Gains and Where Do They Come From?

The Empirical Framework

The Joint Consideration of Technical and Legitimacy Gains

4. EMPIRICAL CONTEXT: SOCIAL MEDIA

What is Social Media?

The Rise of Social Media

Social Media from a Business Perspective

5. DATA AND METHODS

Sample

Variables 
Preliminary Analysis

Estimation Methods

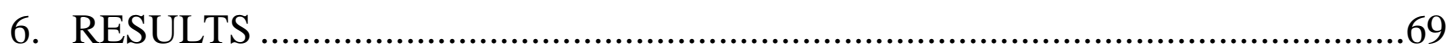

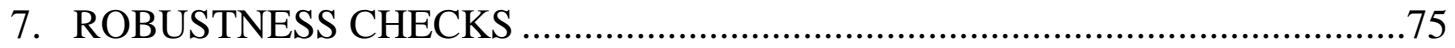

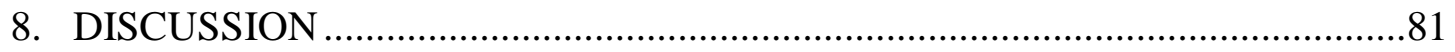

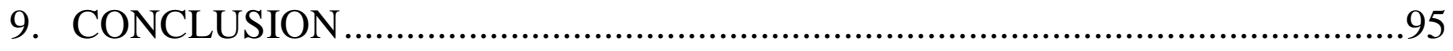

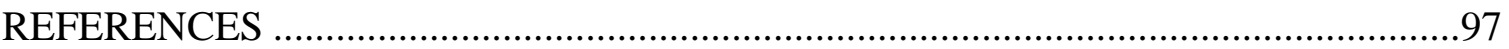

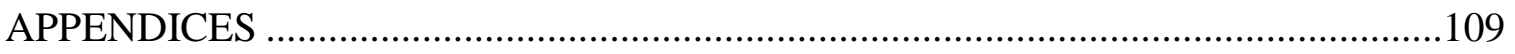

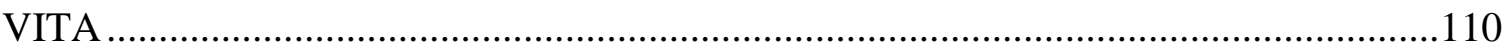




\section{LIST OF TABLES}

Table

1. Classification of Social Media by social presence/media richness and selfpresentation/self-disclosure .46

2. List of Industries in Sample ............................................................................60

3. Descriptive Statistic and Correlations, Combined Models .......................................70

4. Descriptive Statistic and Correlations, Facebook Models …....................................70

5. Descriptive Statistic and Correlations, Twitter Models ..........................................70

6. Descriptive Statistic and Correlations, YouTube Models...........................................71

7. Covariate Adjusted Cell Means, ANCOVA Analogs of Lagged Regression Models...71

8. Impact to Change in Relative ROA, Lagged Regression ..........................................72

9. Impact to Relative ROA for Strategically Aligned Firms, Fixed-effects Time Series ..78

10. Impact to Relative ROA for Late Adopting Firms, Fixed-effects Time Series ...........78

11. Impact to Change in Relative ROA for Strategically Aligned Firms, Lagged

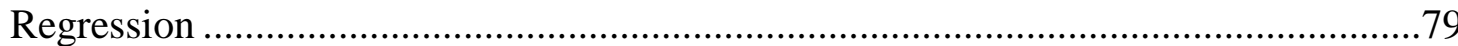

12. Impact to Change in Relative ROA for Late Adopting Firms, Fixed-effects Time Series

13. Impact to Relative ROA for Strategically Unaligned Early Adopters, Fixed-effects Time Series

14. Impact of Formal Adoption and Implementation Effort on Change in Relative ROA 


\section{LIST OF FIGURES}

Figure $\quad$ Page

1. Empirical Frameworks of Technical and Legitimacy Gains at Time of Adoption........36 


\title{
THE INTERPLAY OF LEGITIMACY GAINS AND TECHNICAL GAINS IN THE ADOPTION OF SOCIAL MEDIA
}

\author{
Brent B. Clark
}

Dr. Karen A. Schnatterly, Dissertation Advisor

\begin{abstract}
The benefits of adopting new practices vary: some provide technical efficiency and some are institutions and bestow legitimacy to adopting firms. These distinct benefits have been treated in isolation in the literature, but I argue that they are not isolated at all and in fact, might interact in how they impact firm performance. I develop theory that builds upon recent findings that firms are indeed motivated to achieve both legitimacy and technical gains, whether they are early or late adopters. By utilizing strategic alignment and adoption timing as proxies for adoption motivation, I empirically separate the two adoption logics and enable the investigation of whether they are both achievable, and if so whether they are additive or interactive. I test these ideas in the context of social media and the adoption of Facebook, Twitter, and YouTube. I find that some firms achieve both technical and legitimacy gains through adoption and that the two positively interact to enhance one another.
\end{abstract}




\section{INTRODUCTION}

Why firms adopt innovative practices and with what consequences has been a central focus of management and organization scholars (Meyer \& Rowan, 1977;

Abrahamson, 1991; Westphal, Gulati, \& Shortell, 1997). The issue is critical because isomorphic adoption significantly influences firm social performance as well as substantive economic performance (Heugens \& Lander, 2009). Prior work has offered many insights into the motivations and mechanisms of the relationship between isomorphic adoption and firm performance. One influential example is the two-stage model of adoption motivation (Tolbert \& Zucker, 1983), which suggests that early adopters are motivated by increased economic and technical efficiency while late adopters seek the social benefits of legitimacy. Related work has further suggested that conformance to social norms tends to conflict with efficiency criteria (Meyer \& Rowan, 1977) and that firms must therefore choose between a naturally occurring trade-off involving technical efficiency and legitimacy (e.g., Barreto \& Baden-Fuller, 2006).

Recently, however, Kennedy and Fiss (2009) found that social and economic motivations coexist for both early and late adopters. This raises a multitude of questions hitherto deemed irrelevant because firms were assumed to be motivated by only one or the other, but not both technical efficiency and legitimacy. Not the least among such questions is whether firms are actually capable of simultaneously achieving these dual motives. This paper seeks to answer this question and also determine the nature of the relationship between the social and technical benefits of adopting new practices. 
While the standard answer to institutional theoretic questions is that firms seek legitimacy and survival, not efficiency (Greenwood, Oliver, Sahlin, \& Suddaby, 2008), there has been a recent wave of Institutional Theory scholars acknowledging more fully that managers are not as constrained by their search for legitimacy and survival as previously theorized (Hinnings \& Tolbert, 2008) and they are also not 'sociological dopes' (Heugens \& Lander, 2009) that senselessly adopt any and all aspects of their institutional environment without regard for economic impact. Rather, there is a range of possible forms of conformity that are all capable of bestowing legitimacy (Powell, 1991; Greenwood \& Hinnings, 2006), thus enabling managers in search of legitimacy to adopt institutions without necessarily sacrificing the additional motivation to achieve technical improvements within the organization. Whereas managers were seen as captives of the binding and powerful institutional surroundings, now we see examples of 'sagacious conformity' (Meyer \& Rowan, 1977) and strategic choices (Westphal \& Zajac, 1994) in adoption and implementation decisions, and even the influencing of the institutional environment itself (DiMaggio, 1988).

Coupled with the readmission of managerial discretion into institutional theorizing is the recent finding that, contrary to the standard two-stage model of adopter motivations (Tolbert \& Zucker, 1983), both early and late adopters possess both the motivation to obtain legitimacy and the motivation to improve economic performance (Kennedy \& Fiss, 2009). This raises the additional question of whether legitimacy and efficiency can both be achieved. This is not a violation or even a mild departure from the main tenets of Institutional Theory. Efficiency-seeking firms still operate from within an 
institutional context and still find themselves motivated to gain, maintain, or avoid losing legitimacy and survival. Nevertheless, legitimacy might not be a firm's sole ambition as they adopt institutions. In fact, this is not dissimilar from earlier work that observed that certain types of isomorphic adopters decoupled formal adoption from substantive implementation in an effort to obtain legitimacy without incurring the efficiency downside (Westphal \& Zajac, 1994). The question I now pose is distinct, however, because it is unknown whether it is possible to simultaneously achieve both legitimacy and the efficiency upside. We have evidence that firms want both legitimacy and technical gains (Kennedy \& Fiss, 2009). But to date, there is a lack of empirical investigation into whether these dual motives are in reality compatible and obtainable. Does legitimacy inevitably come at the cost of technical performance, and does the pursuit of technical efficiency unavoidably hamper legitimacy? Furthermore, if legitimacy and technical gains are indeed both achievable, are they strictly additive or do they interact by either enhancing or attenuating each other?

To begin to clarify these issues, I review and modify past definitions of the various terms that refer to social and economic performance in the institutionalism literature. Specifically, technical gains are the benefits that accrue to a firm as a direct consequence of the implementation of an innovation that improves firm operations, and legitimacy gains are those benefits that accrue to organizations as a consequence of legitimacy, whether they be social or economic. This definitional approach is a critical component to empirically isolating the impact of technical and legitimacy gains. Furthermore, in doing so I contribute to Institutional Theory by extending extant theory 
through the development of arguments that suggest the inclusion of late adopters among those that are able to achieve technical gains. Prior work suggests that this combination of firm/adoption characteristics is unlikely to exist (e.g. Tolbert \& Zucker, 1983;

Westphal, Gulati, \& Shortell, 1997) since firms capable of technical gains would have already adopted the practice. However, attention-based (Ocasio, 1997) and top management team cognitive limitations (Bogner \& Barr, 2000; Fiol \& O’Connor, 2003) arguments suggest that, particularly in dynamic business environments, there are likely to be firms that could achieve technical benefits through early adoption but either fail to notice beneficial practices or develop inaccurate estimations of their usefulness. Such firms are not precluded from pursuing and achieving technical gains as late adopters. Utilizing strategic alignment to indicate which firms are capable of achieving technical benefits through adoption of an institution, and using adoption timing to indicate which firms can reasonably expect legitimacy benefits, instead of using adoption timing as an indication of the availability of both technical and legitimacy benefits, is a sharp departure from the two-stage model (Tolbert \& Zucker, 1983). This departure, however allows for the inspection of the two disparate adoption logics in isolation from one another as well as how they might impact one another.

I utilize the adoption of social media practices (Facebook, Twitter, and YouTube) in the shoe, clothing, accessories, and health and beauty aids industries as the empirical context within which I investigate these questions. Not only is there evidence that the utilization of social media has become an institution in these industries, but there are also likely to be many late adopters that can expect technical gains. The strategic alignment 
indicator within these industries that will enable the separation of firms into those that can expect technical benefits to a greater and lesser extent is the categorizing of firms as employing, or not, a degree of differentiation that is aligned with the use of social media. I develop arguments suggesting that moderate to high differentiators, because they are focused on branding and offering unique features, can expect to achieve greater technical gains than firms low or very high on that dimension of strategy. Those firms that pursue a low cost strategy and those that differentiate so highly that customers do not accept online interaction will not benefit from social media adoption. I suggest that medium and high level differentiators will benefit from social media adoption through the instrumentality of information dissemination to consumers as well as information gathering from consumers.

I contribute to the Organizations and Management literatures in several ways. First, I expand upon the two-stage model of diffusion by arguing for the inclusion of late adopters among those that are motivated by and capable of achieving technical gains. Contrary to received theory that claims that firms capable of technical gains will be early adopters (Tolbert \& Zucker, 1983) and that late adopters are only interested in and capable of pursuing legitimacy gains, I develop arguments that explain why not all firms capable of technical gains will adopt early on. Second, this study is the first to empirically confirm that some late adopters actually achieve both the technical and legitimacy gains of isomorphic adoption. This is in strong support of recent work that contends that firms possess both the social and economic motives (Kennedy \& Fiss, 2009). I find that those motives are well founded as some firms actually achieve both. 
These first two contributions enable a third major contribution to institutional theory research. This study is the first to investigate the interplay of legitimacy and technical gains. This topic has been largely overlooked as the two sources of adoption benefits have been considered incompatible (Meyer \& Rowan, 1977) and part of a naturally occurring tradeoff (Barreto \& Baden-Fuller, 2006) where firms must choose between one or the other. I find that the two positively interact to enhance firm performance. Fourth, this study also responds to a recent call to find better proxies for adoption motivation (Kennedy \& Fiss, 2009). Adoption timing has been the standard proxy for adoption motivation where early adopters seek technical gains and late adopters seek legitimacy gains (Tolbert \& Zucker, 1983). This operationalization naturally precludes the simultaneous investigation of both adoption logics as it is unable to combine or separate the two. Instead, it has served to isolate the two in a false dichotomy where all early adopters only want one thing and all late adopters only want another thing. I utilize strategic alignment as a way to identify firms that are capable of benefiting from the adoption of practices that are in harmony with firm strategy and retain adoption timing to identify firms capable of benefiting from legitimacy gains upon (late) adoption.

Finally, the isomorphic adoption of social media is a unique empirical context which also in itself promises to make a significant contribution to the understanding of institutional processes. The field has not seen enough emphasis on understanding the role of the institutional environment outside of highly regulated industries. While institutional norms tend to exert enormous influence in such industries (Deephouse, 1996), their 
influence must also be explored in aspects of the institutional environment other than industry. Governments, cultures, nations, social movements, and consumers and their habits also constitute critical components of the institutional environment. Indeed, the normative standards of the social populace stand to exert an immense influence on which firm behaviors become taken-for-granted or rule-like. As such, the adoption of social media is of particular interest to institutional theory scholars as it represents not only a recently emerged organizational practice, but one that is inextricably linked to social and cognitive processes because it is itself a meaningful form of social exchange.

\section{LITERATURE REVIEW: INSTITUTIONAL THEORY}

\section{Foundations of Institutional Theory}

During the preceding three and a half decades, Institutional Theory has emerged as one of the dominant perspectives in the study of organizations (Palmer \& Biggert, 2002). Its emergence began, in part, as a response to the prevailing perspective of the 1970s that organizations are largely agentic actors that seek to respond to situational constraints. Organizations were seen as rational systems that were designed with the intention of being efficient structures for taking inputs and turning them into outputs. Structural-contigency theory (Burns \& Stalker, 1961; Chandler, 1962; Lawrence \& Lorsch, 1967), resource-dependence theory (Pfeffer \& Salancik, 1978), and population

ecology theory (Hannan \& Freeman, 1977) all focused on how organizations adapt (or fail to adapt) to their environment to best enable them to accomplish adequate 'fit' or 
suitability to survive and thrive within their environment. Furthermore, in each case, an organization's 'environment' was essentially the market context from neoclassical economic accounts where the behavior of leaders or organizations is rational, or at least boundedly so. Against this backdrop, early institutionalists introduced the notion of rationalized myths (Meyer \& Rowan, 1977), the 'common understandings of what is appropriate... behavior' (Zucker, 1983), and the 'rules, norms, and ideologies of the wider society' (Meyer \& Rowan, 1983) as a new element of an organization's environment.

This institutional context provided a new lens through which to consider the rationality of an organization's conduct. Indeed, the central line of inquiry was and still is to understand why, and with what consequences, organizations adopt certain organizational arrangements and behaviors that disregard traditional explanations of rationality. Instead of merely pursuing fit or fitness, it can also be rational to pursue the appearance of having achieved fit or fitness (Scott, 1983). Hence, organizations were theorized to conform to the norms and practices that have achieved taken-for-granted or rule-like status (DiMaggio \& Powell, 1983) in order to signal their fitness and gain legitimacy in the eyes of critical constituents. While this was presumed by some theorists to tend to be in conflict with the exigencies of operational efficiency (Meyer \& Rowan, 1977; Zucker, 1987), mimetic isomorphism and the attendant endowment of legitimacy affords its own set of benefits. Alignment with prevailing norms generates positive social evaluation which should decrease social censure and demands for external accountability while enhancing survivability and opportunities to acquire resources. Because the 
behaviors that deliver efficiency and legitimacy can be at odds with each other it was also theorized (Meyer \& Rowan, 1977; Pfeffer, 1982) and empirically confirmed in later studies (Edelman, 1990, 1992; Westphal \& Zajac, 1994) that conformity may be ceremonial as organizations decouple symbolic practices from the implementation and routinization of actual core operations in an attempt to gain legitimacy while avoiding the downside.

Early theorists conceded that the institutional context will influence all organizations, but placed particular emphasis on those organizations with unclear or difficult to evaluate outputs such as government agencies and non-profit organizations. These entities should be especially sensitive to the need to appear rational under social evaluation due to a lack of (or lack of emphasis on) objective performance targets such as profitability. This focus led to some difficulty in establishing a clear definition of 'institution'. Early confusion stemmed from the fact that an institution can be taken to mean a type of organization such as a mental hospital, prison, or orphanage. An alternative usage is of an institution as a portion or the whole of the framework of the political economy such as the collection of government agencies and policies (e.g. Baron, Davis-Blake, \& Bielby, 1986). I adopt the definition put forth recently by Greenwood and colleagues wherein an institution is understood to mean a 'more-or-less taken-forgranted repetitive social behavior that is underpinned by normative systems and cognitive understandings that give meaning to social exchange and thus enable self-reproducing social order' (Greenwood et al., 2008). This definition identifies the widespread exchange of social norms and understandings as the source of institutional legitimacy and 
also indicates that behaviors are institutions, not just beliefs, and that those behaviors must be manifest with some degree of regularity and with clear meanings attached to them. This definition is ideal because it encompasses many other definitions and it reemphasizes the cultural and symbolic influences from all external sources as the institutional context, of which regulatory or state agencies are just a part. It follows that 'institutionalization' refers to the processes by which something attains the rule-like status imbued with meaning and capable of providing legitimacy (Greenwood et al., 2008). It is also noteworthy that this definition avoids stating how widely practiced an institution is or that it is highly resistant to change, even though these elements are present in some definitions.

Beyond the core question of firm rationalization, DiMaggio and Powell (1983) introduced an additional insight that spurred another of the core questions with which institutional theorist have become (and remained) concerned. They pointed out that not only were firms becoming increasingly bureaucratized, but that as a result, firms were also increasingly homogenous. Their suggestion that the institutional context creates an 'inexorable push towards homogenization' (1983: 148) begged the question: "why is there so much similarity in firm structure and practice?", and led to enormous effort to empirically explore isomorphism. Importantly, they also proposed three mechanisms of institutional diffusion: coercive, which arise when regulators or similarly powerful constituents insist or force compliance with norms; normative, which arise predominantly from professionalization standards; and mimetic, which occur when uncertain organizations mimic the behaviors of leader firms either because those behaviors are 
believed to be rational, or because they believe that adoption will help them avoid appearing deviant. The question of motive has continued to be a critical and defining element of institutional thought because adoptive isomorphic behavior in the absence of institutional rationalizations may not be due to institutional processes at all (Mizruchi \& Fein, 1999). In other words, isomorphism may not be mimetic isomorphism; rather it may be the result of rational economic decision making, vicarious learning, or even a simple lack of options. In fact, many empirical studies published under the guise of institutional theory have mistakenly equated adoption of form or practice with institutional behavior (Hasse \& Krücken, 2008).

While institutional theory scholars have continued, in recent years, to broaden the boundaries and the depth of institutional thought, the basic, foundational elements are briefly summarized here. First, organizations are influenced by their institutional context, especially 'institutionalized organizations' (Meyer \& Rowan, 1977) that have a strong need to appear rational. Second, institutions are widely taken for granted and socially acceptable. Third, organizations conform to institutional pressures (coercive, normative, and mimetic) out of a desire to appear legitimate, which legitimacy provides performance and survival benefits. Fourth, institutional isomorphism may be in conflict with structural or operational efficiency, so conformity may be symbolic and largely decoupled from the actual practical implementation. Fifth, isomorphic adoption and homogeneity are not synonymous with institutional isomorphism; hence the motivation to achieve legitimacy is a crucial element of institutional processes. Most recent developments in the literature largely build upon or fine-tune these foundational tenets. 
Some of these recent developments are central to this current project and will be addressed now as critical building blocks to further theory development.

\section{Recent Developments in Institutional Theory}

Since the 1970s and 1980s, the core issues that institutional scholars seek to answer and better understand are largely consistent with those issues just summarized and of main concern to early theorists. However, the areas of inquiry have extended in many new directions, of which only a few will be discussed here. In particular, there are a number of ongoing debates that are highly salient to the current research objective. The four that will be discussed here are (1) the use of isomorphic mechanisms as a proxy for institutionalization (Mizruchi \& Fein, 1999), (2) the "structure versus agency" debate (Hirsch \& Lounsbury, 1997), (3) the impact of isomorphism on substantive firm performance (Heugens \& Lander, 2009), and finally (4) the disentangling of symbolic and substantive benefits (Lounsbury, 2007). The first debate highlights a need for caution in invoking institutional isomorphism, a concern that will be addressed in this project. The second and third debates establish and stress the need to consider firm motivation and ability to pursue technical gains within an institutional framework. The final debate stresses that there is some confusion regarding whether the technical and legitimacy benefits of isomorphic adoption are indeed different, and if so, how to tease them apart.

First, an ongoing significant tension among scholars is regarding the oversimplistic use of presumed isomorphic mechanisms as a proxy for the existence of 
rationalized isomorphism itself (Mizruchi \& Fein, 1999). With so much emphasis on the phenomenon of isomorphic adoption in the institutional theory literature, it has become common for empirical researchers to measure adoption (or diffusion) while they invoke institutional isomorphism without actually measuring it at all (Boxenbaum \& Jonsson, 2008). Such studies run the risk of drifting into the expansive realms of diffusion or network studies unless care is taken to establish that motives and meanings are consistent with theorized institutional processes. Some of the impetus for the "theoretically treacherous' notion that diffusion is a valid proxy for institutionalization originates from the well-known 'two-stage model' introduced by Tolbert and Zucker (1983) where they assume that diffusion leads to institutionalization. The first stage consists of a rational, economically driven search for technical efficiency while the second is a search for legitimacy wherein efficiency gains no longer predict diffusion. Some argue, however, that an increase in adoption rate may not be a flawless indication that legitimacy is all of a sudden available to second-stage adopters (e.g. Scott, 1995). In fact, the two-stage model closely resembles the traditional two-stage model of diffusion (Katz, Levin, \& Hamilton, 1963) with the second stage simply renamed as the institutional phase instead of the contagion phase (Boxenbaum \& Jonsson, 2008). In light of the potential misapplication of one of institutional theory's main phenomena, it is critical to determine whether a firm is motivated to adopt because they believe it will bestow legitimacy as opposed to other adoption rationales such as organizational learning. This offers a simple but crucial litmus test to be used in determining whether a particular behavior is an institutional activity. In fact, many leading scholars consider legitimacy to be the decisive element of institutional explanations (e.g. Greenwood et al., 2008; Haveman \& 
David, 2008). In other words, widespread diffusion is indicative of, but not a sufficient condition for a behavior to have achieved status as a taken-for-granted, legitimacyproviding institution. Nevertheless, it is critical to note that firms can be motivated to seek legitimacy and technically rational benefits simultaneously (Kennedy \& Fiss, 2009). Consequently, efficiency seeking firms do still operate within and are likely to be influenced by their institutional environment and therefore remain a valid option for meaningful investigation by scholars utilizing an institutional theory lens.

A second crucial debate within institutional theory, often referred to as the “structure versus agency" debate (cf. Giddens, 1984; Dacin, Goodstein, \& Scott, 2002), is how forceful institutional contexts are and, therefore, how much leeway exists for organizations to strategically and selectively respond to coercive, normative, and mimetic pressures. One virtue of the definition of 'institution' provided by Greenwood and associates (2008) is that it avoids overstating either side of this debate by deliberately avoiding stating how widely adopted or how long lasting an institution is. At issue is whether institutional contexts universally point firms in the same direction, both in terms of the adoption decision (yes or no) as well as in the nature and extent of the adoption implementation. Conflicting arguments exist regarding how formidable the institutional context is (and hence how universal isomorphic adoption will be) as well as regarding the malleability of institutions (Hinnings \& Tolbert, 2008). Meyer and Rowan (1977) consider institutions to be 'binding' and 'powerful' forces that leave little opportunity for individual discretion. Likewise, Tolbert and Zucker (1983) suggest that organizations are 'captives of the institutional environment in which they exist'. Essentially, continually 
increasing institutional pressure and structuration constrains organizational agency, leading to greater and greater homogeneity with less and less ability to defy these forces (Hoffman \& Ventresca, 2002). On the other hand, the notion of intentional decoupling (Westphal \& Zajac, 1994) implies a degree of managerial discretion and strategic choice on the part of organizational actors. Organizations may even face multiple, conflicting, or varied institutions that make it impossible to conform to them all (Brunnson, 1989). Furthermore, Powell (1991) has suggested that there is often a range of acceptable responses to institutional pressures that are equally or nearly equally valid in bestowing legitimacy. An even more extreme stance is that organizations often play an active role in shaping and promoting new or evolving elements of the institutional environment (Meyer \& Rowan, 1977), a behavior now termed institutional entrepreneurship (Battilana, Leca, \& Boxenbaum, 2009; DiMaggio, 1988).

Third, one of the more interesting debates within institutional theory focuses on whether isomorphism is negatively or positively related to substantive firm performance. On one hand, institutions are theorized to hamper efficiency because they are forced upon a firm with no regard for whether they are beneficial. Indeed, it was suggested early on that, "conformity to institutionalized rules often conflicts sharply with efficiency criteria" (Meyer \& Rowan, 1977: 340). If isomorphic adoption is expected to negatively influence technical efficiency, isomorphic adopters will adopt with legitimacy as a goal and tend to adopt the symbol of an institution more than the substance (Westphal \& Zajac, 1994), making it performance neutral at best and performance diminishing at worst (Meyer \& Rowan, 1977). Firms may accomplish the adoption of the 'symbol' by announcing the 
intention to adopt a practice and never following through or only following through with visible but low cost effort. Furthermore, because legitimacy creation is often (ironically) built upon the efficiency motives of early adopters, later adopters are less likely to have perceived a fit with the practice and firm strategy (Westphal, Gulati, \& Shortell, 1997), else they would have already adopted. As such, isomorphic adopters are likely to view conformance and performance as tradeoffs (Barreto \& Baden-Fuller, 2006), and even if they do adopt, they will tend to avoid full implementation (Westphal \& Zajac, 1994). Additional suggested reasons to theorize a negative relationship between isomorphism and substantive firm performance are positive opportunity costs of the resources invested in conformity behaviors (Barreto \& Baden-Fuller, 2006) and a decreased ability to meaningfully differentiate oneself from competitors (Deephouse, 1999) thus lowering the ability to achieve sustainable competitive advantage.

On the other hand, because many practices become institutions precisely because they represent efficient ways of doing things that evolve into taken-for-granted ways of doing business (Westphal, et al., 1997), isomorphic adoption has the potential to enhance firm performance. Along these lines, Kennedy and Fiss (2009) have argued that a desire to appear legitimate should only conflict with the desire to improve performance if performance improvements themselves are widely perceived as illegitimate. This perspective stresses that there are likely to be institutions that need not involve a strict tradeoff involving conformity and performance, such as TQM adoption among hospitals (Kennedy \& Fiss, 2009; Westphal, Gulati, \& Shortell, 1997). Scott and others have also noted that organizations often encounter institutional contexts that provide a 'choice set' 
which allows for varied, yet equally legitimate, responses (Scott, 1983; Greenwood \& Hinnings, 2006) wherein managers have the ability to exercise 'sagacious conformity' (Meyer \& Rowan, 1977). In short, managers are influenced by, but not slaves to the social pressures of institutions, and are able to wisely enact strategies that pursue balance between substantive and symbolic performance. One main argument in support of a positive impact to substantive performance that is itself strongly rooted in institutional theory is that isomorphic adopters will be better able to obtain higher quality or lower cost resources (Deephouse, 1999). Because conformity signals rationality, lower risk, and competence, resource providers will prefer conformists as business partners (Baum \& Oliver, 1991; Higgins \& Gulati, 2003). In support of the performance side of the debate, a recent meta-analysis by Heugens and Lander (2009) finds that adoption of isomorphic templates exerts a positive, medium-sized effect on substantive firm performance.

A final ongoing discussion amongst organizational scholars is the disentangling of symbolic and substantive benefits. Since Carroll and colleagues (Carroll, Lee, \& Rao, 1986) pointed out that the very market contexts that define substantive performance are themselves institutionally defined it has been increasingly widely acknowledged that separating the outcomes of institutionally motivated behaviors from the outcomes of traditionally more 'rational' behaviors, such as efficiency seeking and vicarious learning is problematic (e.g. Zucker, 1987; Powell, 1991; Thornton, 2004; Lounsbury, 2007). Although the notion of institutional logics provided a way to ease the distinction between traditional rationality (e.g. the pursuit of efficiency) and institutional pressures by considering technical rationality to be socially defined (Friedland, 2002), the preference 
to theoretically separate them (e.g. Kennedy \& Fiss, 2009) and their benefits (e.g. Barreto \& Baden-Fuller, 2006) has hardly subsided. Despite the observation that institutional theory may simply deal with multiple types of rationality (logics) that may not need to be kept separate, the majority of scholars continue to approach their research agendas with the earliest conceptualizations of institutional processes kept separate and unique from technical rationality. This is evidenced by the extensive and continued separation of symbolic and substantive performance in measures, theorizing, and hypothesizing (for a list see Heugens \& Lander, 2009). Even projects that suggest that both legitimacy and efficiency coexist as simultaneous motivations within firms still maintain the distinction that they are different types of motives with potentially different outcomes (Kennedy \& Fiss, 2009).

The current project relates to each of these four ongoing debates within institutional theory and will contribute to greater understanding of the limitations and boundaries of the various arguments. In particular, it moves beyond what Kennedy and Fiss (2009) have accomplished vis-à-vis the disentangling of symbolic and substantive benefits by investigating actual performance outcomes of isomorphic adoption due to both legitimacy and technical gains, in isolation and in combination.

The isomorphic adoption of social media is a unique empirical context which is also in itself an additional reason this study has the potential to contribute to understanding institutional processes. Understanding the benefits available to firms that seek social approval must be pursued more generally than solely highly regulated industries. While institutional norms tend to exert enormous influence in such industries 
(Deephouse, 1996), their influence must also be explored in less stringently regulated industries. Governments, cultures, nations, social movements, and consumers and their preferences also constitute critical components of the institutional environment. Indeed, the normative standards of the social populace stand to exert an immense influence on which firm behaviors become taken-for-granted or rule-like. As such, the adoption of social media is of particular interest to institutional theory scholars as it represents not only a recently emerged organizational practice, but one that is inextricably linked to social and cognitive processes because it is itself a meaningful form of social exchange.

\section{THEORY AND HYPOTHESIS DEVELOPMENT}

In this section I will address the question of whether legitimacy and technical gains are both achievable and if so, how they interact. To do so, I will briefly recall some of the major tensions within the institutional literature, develop arguments that resolve these tensions, and then develop several novel hypotheses. The first step will be to discuss isomorphic adoption and its benefits: the current ways of approaching the topic, some of the shortcomings of these approaches, and theoretical extensions that improve upon existing conceptualizations. Second, these extensions necessitate a discussion of how to disentangle the outcomes of technical and legitimacy gains. Prior work identifies difficulties in doing so that will be addressed. Third, a discussion of the timing implications of technical and legitimacy gains will help further resolve existing tensions and sets the stage for the fourth and fifth pieces of this section: new formal definitions of 
technical and legitimacy gains, accompanying discussions of their sources, and hypotheses about their impact to the performance of isomorphic adopters. Sixth, the complete empirical framework will be briefly presented and followed by the development of theory and hypotheses regarding the intersection of technical and legitimacy gains.

\section{Isomorphic Adoption and its Benefits}

Why certain firms adopt new organizational practices has been a central focus of research in the management and organization theory literatures for some time (e.g. Abrahamson \& Rosenkopf, 1993; Westphal, Gulati, \& Shortell, 1997). Understanding when and why firms adopt or fail to adopt new practices is crucial because the adoption of new practices can influence organizational performance (Meyer \& Rowan, 1977; Lee \& Pennings, 2002; Barreto \& Baden-Fuller, 2006). The institutional perspective suggests that organizations often adopt established practices out of a desire to be perceived as legitimate (DiMaggio \& Powell, 1983). While not a core tenet of Institutional theory, scholars in this arena also tend to acknowledge that firms may adopt new practices due to the "other" motivation: the economically rational pursuit of technical or efficiency improvements (e.g. Teece, 1980; Katz \& Shapiro, 1987). Regarding the first of these two distinct motives, considerable consensus exists among scholars that isomorphic adoption does indeed provide organizations with legitimacy, or positive social evaluations (Deephouse \& Suchman, 2008). However, there is less clarity regarding the impact of isomorphic adoption on firm economic performance. On one hand, institutions are theorized to hinder performance because they conflict with efficiency criteria (Meyer \& Rowan, 1977) and are forced upon firms with no regard for whether they are beneficial. 
On the other hand, many institutions are not at odds with firm performance and may have become institutions precisely because they improve performance (Westphal, Gulati, \& Shortell, 1997). The two divergent perspectives may relate to the fact that many early theorists focused on industries characterized by significant compulsory state regulations. These coercive institutions are imposed in order to reign in socially damaging firm behaviors in order to protect consumers, the environment, and society at large and are not typically designed with efficiency in mind. Through this early lens, that particular type of institution became a main type around which theorizing centered, leading to the conclusion that isomorphic adoption has efficiency costs with little or no efficiency benefits. Certainly, there is potential for this type of institution, even as it allows a firm to avoid negative sanctions and legitimacy loss, to damage the efficiency of firm operations while other types of institutions of a more mimetic and normative nature have the potential to be efficiency enhancing. Despite the limiting assumptions regarding the adoption of institutions and efficiency, even when done for institutional motives isomorphic adoption is often positively related to accounting-based profitability as supported by Huegen and Landers' recent meta-analysis (2009). The major implication of this conclusion is that the adoption of institutions can provide not only legitimacy, but can also positively influence economic performance either due to legitimacy benefits that indirectly impact firm economics, technical benefits that directly relate to operational efficiency, or some combination of the two. The performance implications of this conclusion will be developed later on, but it is also important in terms of understanding the motivations of firms as they adopt innovative practices in pursuit of both social approval and improved performance. 
These two motivations to adopt have been combined into the classic two-stage model (Tolbert \& Zucker, 1983) which suggests that early adopters of a new practice do so with the intention of achieving efficiency or technical gains while late adopters are only interested in either gaining or avoiding the loss of legitimacy (Westphal \& Zajac, 1994). While this model allows that a firm may achieve technical benefits and a firm may gain legitimacy benefits it does not allow that firms may achieve both. More precisely, and based on the timing of adoption, (a) firms are not motivated to seek both types of benefits and (b) firms cannot achieve both types of benefits. In essence, "conformance scholars" (Heugens \& Lander, 2009) describe legitimacy and accounting-based profitability as a tradeoff where firms must either choose between conformance and performance (Barreto \& Baden-Fuller, 2006) because the adoption of institutions conflicts with technical efficiency. In this quandary, managers may feel pressure to "do something" to signal legitimacy even though it may not make strategic sense (Dean \& Snell, 1996). Evidence of these as conflicting goals is seen in the choice of many firms to adopt the symbol of an institution without implementing the substance of it into the actual routines and daily operations (Westphal \& Zajac, 1994). While this strategy may not be available in all cases, such as the adoption of regulatory institutions, by decoupling adoption and implementation they are able to establish a façade of conformity without the full burden of implementing something detrimental to firm operations. Although certainly not true for all late adopters, some of them may in fact face this tradeoff since they chose not to adopt early because they perceived no obvious technical benefits from adoption (Westphal, Gulati, \& Shortell, 1997). As a consequence, the argument is extrapolated to include all late adopters with the suggestions that, in general, later adopters have no 
interest in fully adopting the substance of an institutionalized practice and opt to adopt the symbol, resulting in achieving legitimacy benefits as well as incurring the minimal efficiency costs of social conformity. This tradeoff rationale assumes that late adopters do not expect or are unable to derive technical benefits from adoption and careful implementation of a new practice. This may be true for some firms that adopt only the symbol and therefore poorly implement a practice, as some late adopters do (Westphal, Gulati, \& Shortell, 1997). However, this may not be true for other firms that for one reason or another fail to adopt a beneficial practice early on, but that pursue late adoption with adequate levels of implementation investment (Ritchie \& Melnyk, 2012).

Contrary to the position adopted by proponents of the two-stage model, many late adopters are capable of achieving and are motivated to seek technical benefits (Kennedy \& Fiss, 2009) from the adoption of institutions. Late adopters can be capable of achieving technical benefits because firms that could have achieved technical benefits from early adoption but chose not to might still reasonably expect technical benefits as a late adopter. While the two-stage model suggests that such firms do not widely exist, there are at least three explanations for why they do exist: lack of awareness, lack of judgment, and newly formed organizations. First, firms with the ability to accurately judge the technical benefits of an innovative practice may still not adopt early on if they are not aware of the practice in its infancy. The behavior of decision makers depends on what issues they are able to give their attention (Ocasio, 1997). Similarly, firm behavior is tied to how they distribute and regulate the attention of their decision makers (Scott, 1992). This is a process of allocating finite firm-level resources, meaning firms are unable to allocate attention to all relevant issues. Firms indirectly choose which issues to 
give attention to through the formulation and implementation of firm-specific structural distribution, strategy, and culture (Ocasio, 1997). Furthermore, the situational context plays a role in determining what attracts attention (Ross \& Nisbett, 1991). In short, limited attentive resources constrain organizations to pay attention to only a fraction of potentially relevant issues and events. This may be especially true in highly dynamic business processes such as branding activities, where managers have too many things to pay attention to in order to be able to successfully notice and correctly judge the usefulness of every new practice their industry competitors try. Second, due to cognitive limits, top managers do not develop a complete understanding of their surroundings (Bogner \& Barr, 2000; Fiol \& O'Connor, 2003). Consequently, top managers develop subjective interpretations of their competitive environment that lack objectivity and accuracy (Nadkarni \& Barr, 2008). Firms may mistakenly determine an innovative practice to have no value and choose not to adopt when they should have. This same firm may then later adopt once they see that they are expected to do so. Despite adopting with the sole intention of seeking legitimacy, they essentially stumble upon a useful practice that enhances both legitimacy and technical efficiency. This is a particularly appealing notion because, ironically, the institutionalization of many new practices is built upon the positive market feedback received by the efficiency seeking early adopters (Scott, 1987; Zucker, 1983). In short, some institutions have become such precisely because they represent good ways of doing business and firms may misjudge the usefulness early on, but adopt later on only to find that perhaps they should have done so much sooner. Third, new organizations frequently come into existence. New firms that emerge subsequent to the institutionalization of a practice are not limited to seeking legitimacy 
gains through adoption despite their potential categorization as a late adopter. They, of course, did not choose to forego adoption due to a perceived lack of technical benefit. The awareness, judgment, and existence explanations for the availability of technical benefits to late adopters represent ways to circumvent the limiting assumptions of the tradeoff perspective. An additional argument against the split motivations of the twostage model calls into question the fundamental assumption of the tradeoff itself.

Recently, scholars argue that the choice between conformance and performance is itself a false dichotomy (Kennedy \& Fiss, 2009) because managers are not "sociological dopes" that senselessly adopt any and all aspects of their institutional surroundings (Heugens \& Lander, 2009; Donaldson, 1995). Indeed, managers are able to practice “sagacious conformity" (Meyer \& Rowan, 1977) wherein there exists a range of acceptable responses to institutional pressures that are all able to bestow legitimacy (Powell, 1991; Greenwood \& Hinnings, 2006). Furthermore, the tradeoff perspective has already been empirically challenged. It has been shown that both motivations coexist for both early and late adopters (Kennedy \& Fiss, 2009). This acknowledgment is critical because it suggests that past work that has inferred solitary and independent motivations through behaviors and their timing are inaccurate at worst and incomplete at best. Managers may adopt early or late and still have the motivation and potential to benefit from legitimacy and technical improvements. Therefore, it is important to reassess and seek a more nuanced and empirically supported understanding of whether those motivations are compatible, and if they are, how they might interact. 


\section{The Difficulty of Separating Legitimacy and Technical Performance Gains}

Because most institutional theorists have assumed that firms do not possess the motivation or ability to pursue and achieve legitimacy and efficiency (through a single isomorphic adoption event), little effort has been made to investigate both types of benefits simultaneously. Even the recent work by Kennedy and Fiss (2009) was limited to firm motivation and did not investigate whether those motivations are actually realized. It is an important step forward to acknowledge that efficiency seeking firms still operate within an institutional environment and want legitimacy. But, clearly, legitimacy is not the only thing on their mind. Past work has observed this dual motive in play as firms decouple formal adoption from substantive implementation in order to gain the legitimacy upside while avoiding the efficiency downside (Westphal \& Zajac, 1994). I suggest that the implications of the dual motive are equally compelling regarding firms that adopt institutions with an eye towards the positive influences of both legitimacy and efficiency. Two difficulties in the investigation into whether these dual motives are compatible that will be further addressed are (1) the varied terminology and (2) the issue of simultaneously determining the impact of two distinct causes to performance.

First, the various nomenclatures for legitimacy and technical benefits are problematic and require clarification. For example, the benefits of legitimacy are referred to elsewhere as symbolic performance (Heugens \& Lander, 2009) and social gains (Kennedy \& Fiss, 2009) in addition to simply legitimacy gains. The use of 'symbolic' and 'social' seem to intimate that there is no relationship between legitimacy and accounting-based firm performance despite acknowledgements that legitimacy does indeed influence firm profitability. Similarly, economic or efficiency benefits, which 
may also flow to isomorphic mimickers to the extent that the adopted practice improves the operational functionality of the organization, are referred to in a number of ways. This type of benefit, which I refer to as technical gains are called efficiency gains (Tolbert \& Zucker, 1983), substantive performance (Heugens \& Lander, 2009), and economic gains (Kennedy \& Fiss, 2009) elsewhere. I judiciously avoid referring to this type of benefit as economic or efficiency since legitimacy benefits can also lead to positive economic outcomes, which leads into the second difficulty.

While it may not always be possible to disentangle whether the benefits of adoption are due to increased legitimacy, the benefits of the adopted practice itself, or both (Thornton, 2004), they are theoretically distinct sources of benefits. This is particularly problematic when performance is measured using accounting-based measures because both legitimacy and technical improvements impact firm economics, albeit through different mechanisms. For instance, prior work suggests various mechanisms for legitimacy to influence firm performance, such as avoiding regulative penalties, minimizing demands for extensive accountability signals, and improved ability to acquire resources at favorable terms (Greenwood et al., 2008), each of which relate directly or indirectly to profitability. In comparison, technical gains from new technologies or organizational forms relate to profitability through the actual adoption of the innovation itself and its implementation within the routines and operations of the firm. It is important to note that the impact of legitimacy to firm performance is often also investigated in terms of firm symbolic performance (Deephouse \& Suchman, 2008; Heugens \& Lander, 2009) in addition to substantive economic performance. Thus, while legitimacy has an additional theoretical performance component, legitimacy and technical 
gains are not altogether different in their ability to influence final economic outcomes, rather they come from different causes. The solution to this difficulty of separating the two influences to firm performance lies in isolating them at their origin, not in their manifestation. Generally, this has been attempted by measuring motives and/or adoption timing and assuming that early adopters want technical improvements while late adopters want legitimacy, hence any performance improvements that accrue to those firms are due to those causes (i.e., Scott, 1995; Pangarkar \& Klein, 1998; Westphal \& Zajac, 1994). Motive, however, does not define an outcome, rather it impacts the actions taken, which actions can be identical for firms adopting an institution for widely divergent reasons. Thus, measuring motive can be an important beginning to this effort, but is not sufficient. Indeed, recent work is highly suggestive that motivations for legitimacy and technical gains are much less disjoined than previously conceptualized anyway (Kennedy \& Fiss, 2008; Schneiberg \& Soule, 2005; Scott, Ruef, Mendel, \& Caronna, 2000). Therefore, it becomes important to first acknowledge that legitimacy and technical gains are theoretically dissimilar and then attempt to better understand if the dual motives are compatible and how they may influence one another in their impact on firm performance. Prior to that, however, it is helpful to first note that there are key timing implications concerning the achievement of technical and legitimacy gains.

\section{The Timing Implications of Technical and Legitimacy Gains}

A more complete understanding of the organizational consequences of isomorphic adoption, both technical and legitimacy consequences, requires the integration of temporal influences. The timing implications of, first, technical gains, and then, 
legitimacy gains are discussed. First, the benefits derived from improved efficiency of operations are not temporally constrained. They will accrue to firms at the time of adoption and successful implementation. However, there are at least two reasons why timing may be an issue in determining the economic impact of adoption and implementation of practices that provide technical gains. First, because many innovations require some degree of capital or resource investment, the accounting-based period profitability measures may not reflect the full potential for economic improvement for the accounting period during which any one-time adoption and implementation costs occurred. In this way, the first accounting period subsequent to adoption implementation is uniquely burdened with one-time costs that may mask any perpetual profitability improvements. Second, many new practices involve a learning curve where efficiency of the practice improves as the organization learns how to minimize the costs and maximize the benefits of a practice. In each case, the long-term economic impact to a firm may not be evident at the point of adoption, but may become clearer in subsequent reporting periods.

A second timing issue with technical gains relates to competitive forces (and terminology). Financial success is frequently addressed in relative terms, that is, relative to competing firms. For example, the notion of competitive advantage refers to performance relative to industry competitors. Within a framework of this nature, such as the resource-based view (Barney, 1991), technical gains may appear to be short lived and erode over time as other firms adopt and the profitability increase caused by adoption evaporates. In fact, the technical gain is still present, but it is also eventually present in 
many other firms. In this scenario, were a laggard firm to adopt the then common practice, they too could achieve the technical gain and the corresponding increase in profitability. Indeed, both firms arrive, in the end, at competitive parity albeit by different paths. This acknowledgment is helpful for two reasons. It helps avoid the fallacy that late adopters cannot achieve technical gains simply because late adoption cannot lead to competitive advantage. It is also helpful in noting that a lagged performance measure will become a less relevant assessment of the impact of an innovation adoption event the greater the lag.

The investigation of legitimacy gains has its own set of timing issues. In contrast to technical gains, legitimacy gains are temporally constrained. They are limited to the period of time during which relevant external constituents actively recognize a new practice as having achieved rule-like status (cf. Ritchie \& Melnyk, 2012). In other words, legitimacy benefits will not accompany an innovation adoption event unless the practice is already an institution. This is not to say that the benefits of legitimacy will not eventually be realized by early adopters, rather that it will not occur unless and until the practice later becomes an institution, capable of conferring legitimacy. Similar to technical gains, legitimacy gains should not erode, provided that the institutional environment maintains the adopted practice as legitimate. Because adoption may entail implementation costs and because other firms may also adopt, essentially competing away profits, the timing implications of technical gains seem to apply here as well with possibly the exception of learning curves playing a role. In short, there is a key commonality and a key distinction between the timing implications of technical and 
legitimacy gains. The key commonality is that an ideal measure of the impact to economic firm performance may require a lag, but not too great a lag, while the key distinction is that technical gains are available at the time of adoption to early and late adopters whereas legitimacy gains are available at the time of adoption only to late adopters, although they may become available sometime after adoption for early adopters.

\section{What Are Technical Gains and Where Do They Come From?}

The notion of technical gains is lightly developed in the institutional theory literature, but by and large refers to enhancements in the way business is done. Thus, technical gains are the benefits that accrue to a firm as a direct consequence of the implementation of an innovation that improves firm operations. Examples of technical gains include innovations that reduce waste, improve product quality, save time, or that require fewer inputs (e.g., Tolbert \& Zucker, 1983). Technical gains can also be realized through organizational improvements such as a more efficient reporting structure or a structure that enhances the ability of valuable information to flow to where it can be used. Technical gains improve firm economic performance provided that the benefits are not offset by associated costs (such as implementation costs or unintended consequences) that match or exceed the benefits.

The source of technical gains is dependent upon the characteristics of the firm seeking to improve operational efficiency. This is the case for several reasons. First, many practices can only be implemented a single time and firms that have already 
adopted cannot expect to do so again and receive a similar improvement. Second, firm heterogeneity dictates that firms have different needs. Similarly, industry level heterogeneity dictates that a particular practice may not be universally beneficial across distinct environments with varying levels of dynamism, complexity, or competition. Third, firm strategy dictates that not all innovations that may benefit certain industries or types of firms will fit with the strategic intent of a given firm. An example of this last explanation is the difference in firms that pursue a differentiation strategy versus a cost leadership strategy (Porter, 1980). Adopting a manufacturing innovation that increases both quality and cost of a product may be a boon to the differentiator but be the undoing of the low cost provider. To date, research on institutional processes has focused on pointing out that, in a case such as the cost leadership versus differentiation example, the differentiators will be early adopters and the cost leaders, should the practice become an institution, will be late adopters. Hence technical gains are the motive (and outcome) of the early adopters and legitimacy is the motive of the late adopter. However, measuring the motive does not accurately segregate the firms that can realistically achieve technical gains unless all of the differentiators noticed and adopted the practice early on. Since we now know that both early and late adopting firms want technical and legitimacy gains and since it is probable that some firms that could have profitably adopted early on failed to do so, it is useful to determine which firms are strategically aligned with an innovation as an indicator of the potential technical consequences of adoption. This approach will allow for a more fine grained investigation into the adoption consequences of both legitimacy and technical gains than has been previously accomplished and is a building block for further theoretical development in looking jointly at the impact of legitimacy 
and technical gains resulting from the adoption of institutions. But first, the adoption of emerging innovations that are aligned with firm strategy should benefit adopters through the achievement of technical gains. For early adopters, improvements to firm performance that are attributable to the adoption of a new practice will not be due to the benefits of legitimacy since, early on, a practice is not yet taken for granted or expected and cannot lend legitimacy to the adopter. For strategically aligned late adopters, improvement to firm performance due to technical gains should be achievable in spite of, or regardless of any legitimacy impact from adoption.

Hypothesis 1. For firms whose strategy is aligned with an innovative practice, adoption will positively impact financial performance.

\section{What Are Legitimacy Gains and Where Do They Come From?}

Legitimacy is a term that is widely used, occasionally described but rarely defined (Suchman, 1995). While the definitions that do exist often emphasize whether organizations are understandable and/or desirable, in the most general sense, legitimacy is simply social approval. I adopt a broad definition put forth by Suchman (1995) that also acknowledges the social audience as a critical component:

Legitimacy is a generalized perception or assumption that the actions of an entity are desirable, proper, or appropriate within some socially constructed system of norms, values, beliefs, and definitions.

And, in turn, legitimacy gains are those benefits that accrue to organizations as a consequence of legitimacy, whether they be social or economic. Legitimacy emanates from socially constructed perceptions or assumptions of observers and serves to make 
firms interpretable to external parties, which reduces the uncertainty surrounding what they are and whether they are "rational". While legitimacy can be obtained and retained despite some degree of deviation from social norms (Perrow, 1981), especially if these are relatively few in number or go unnoticed, legitimacy is generally the consequence of conformance to the norms and practices that have achieved taken-for-granted or rule-like status (DiMaggio \& Powell, 1983). Practices that have not achieved this status do not confer legitimacy although they may be beneficial to adopters in other ways, such as through technical gains. Some examples of legitimacy gains are the ability to avoid punitive measures by regulators or governments (Donaldson, 1995), advantageous access to external resources (Zimmerman \& Zeitz, 2002), and an increased probability of survival (Singh, Tucker, \& House, 1986). Because the consequences of achieving legitimacy are not isolated to symbolic aspects of performance, but can also impact efficiency aspects of firm performance, and as a replication of past findings in the literature, I posit that adopters of an innovative practice that is or is not aligned with firm strategy will, nonetheless, benefit from adoption provided that the practice has previously become an institution. Legitimacy gains will be available to all firms that adopt at or after the point in time that the practice has become taken for granted, expected, and is thus capable of bestowing legitimacy.

Hypothesis 2. For firms that adopt late, adoption will positively impact financial performance.

Where related terms such as social performance and symbolic performance are specifically devoid of efficiency or economic performance implications, this definition of 
legitimacy gains can include both economic and non-economic outcomes to an organization due to the direct or indirect outcomes of possessing or gaining legitimacy. I henceforth avoid the more specific terms except in reference to those more limited concepts. Similarly, the more generic terms that are often closely associated with technical gains, such as economic performance, substantive performance, and efficiency, will henceforth be avoided since they can refer to the outcomes of both legitimacy and technical influences except in reference to those broader concepts.

\section{The Empirical Framework}

Thus far, technical and legitimacy gains have been developed independent of one another in such a way that their impact to adopting firms can be insulated from the effect of the other. Early adopting firms that have strategic alignment with a new practice have no possibility of benefiting from legitimacy gains at their time of adoption: the impact of adoption to firm performance is isolated to technical gains. Similarly, late adopting firms that are not strategically aligned with a new practice have no possibility of benefiting from technical gains: the impact of adoption to firm performance is isolated to legitimacy gains. These parts of the overall framework are depicted as the second and fourth quadrants of Figure 1. However, the two dimensions of adoption behaviors discussed here, strategic alignment and adoption timing, have not been considered jointly in terms of their impact to firm performance through both technical and legitimacy gains. 


\section{FIGURE 1}

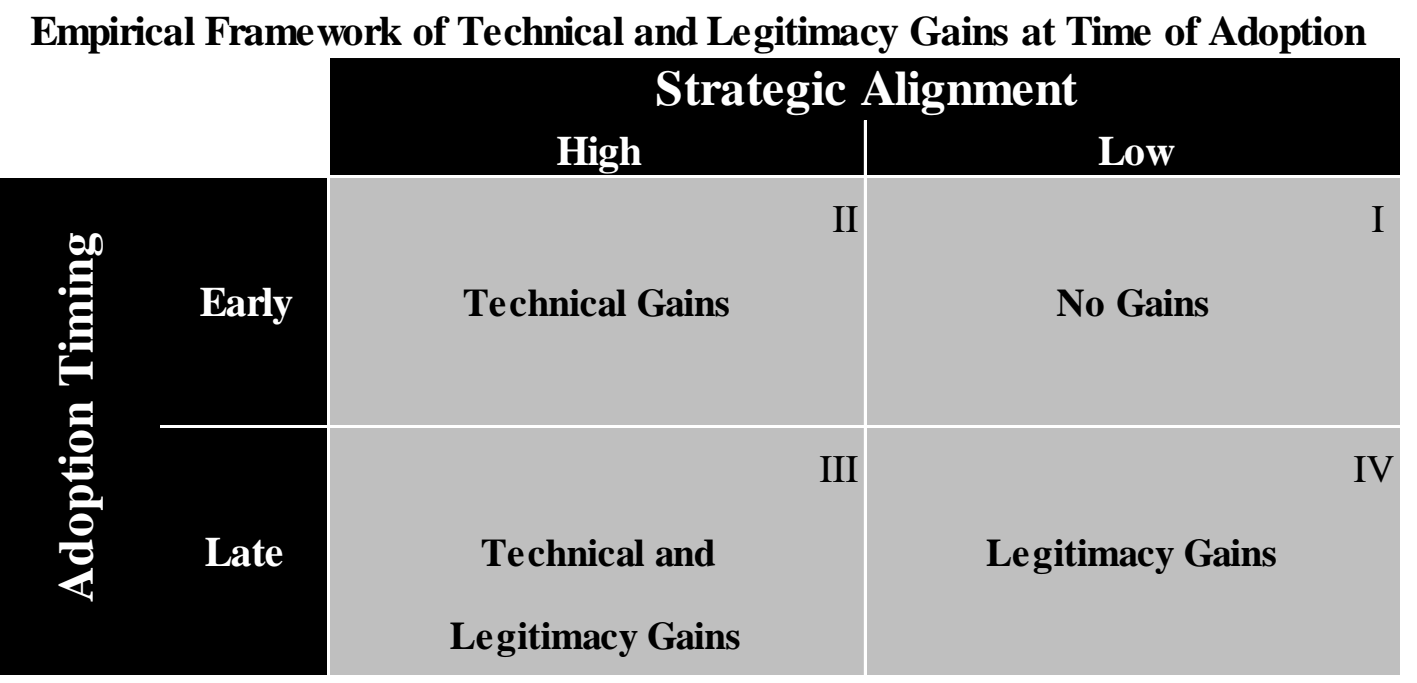

\section{The Joint Consideration of Technical and Legitimacy Gains}

Prior work that has investigated the joint consideration of both technical and legitimacy gains has theorized that the logics of legitimacy and technical performance conflict (e.g. Barreto \& Baden-Fuller, 2006; Basu, Dirsmith, \& Gupta, 1999) with one notable exception being a recent study by Kennedy and Fiss (2009) on the adoption of TQM among hospitals. Perhaps the most influential of studies to integrate the legitimacy and technical perspectives is the two-stage model put forth by Tolbert and Zucker (1983). According to the model, early adopters seek technical gains while later adopters are primarily concerned with the social repercussions of appearing legitimate. They observed that civil service reforms were first motivated by the need to overcome administrative difficulties, but as adoption began to be perceived as a requirement, cities that had not yet adopted faced social disapproval and sanctions. The authors concluded that later adopters, therefore, implemented reforms primarily for legitimacy. This approach has been the underpinning of a significant subsequent stream of work despite a 
lack of evidence that the motivations are indeed mutually exclusive. In fact, it has been pointed out that most of these studies have relied on indirect inferences of motivations based on firm characteristics or post adoption behaviors instead of directly measuring them (e.g. Donaldson, 1995; Scott, 1995). This shortcoming, combined with a number of studies that have failed to support the two-stage model (Sherer \& Lee, 2002; Kraatz \& Zajac, 1996; Lawton \& Wholey, 1993; Goodstein, 1994; Ingram \& Simons, 1995), justifies skepticism that practices that become institutions, often precisely because they improve technical performance, will be unable to do so for and undesirable for that purpose to late adopters. Indeed, the prospect of technical adoption benefits, especially when those benefits can be combined with the allure of improved legitimacy, should provide strong incentive for many late adopters to seek those benefits. Furthermore, and as stated by Kennedy and Fiss, "logically, the desire to appear legitimate should only conflict with a desire to improve performance when performance improvements themselves are illegitimate" (2009), which is arguably the rare exception rather than the rule. In short, the potential for legitimacy gains does not itself preclude technical gains from being desired or achieved. Because technical gains and legitimacy gains should be compatible in most cases, late adopters of institutionalized practices that are aligned with their strategy will experience a greater performance improvement than firms that should merely expect either technical gains (early adopters with strategic alignment) or legitimacy gains (late adopters without strategic alignment). In other words, I suggest that technical and legitimacy gains are not mutually exclusive substitutes subject to a tradeoff decision by adopting firms. 
Hypothesis $3 a$. Late adopters of innovative practices that are aligned with firm strategy will have a greater improvement in financial performance at the time of adoption than early strategically aligned adopters at the time of adoption.

Hypothesis 3b. Late adopters of innovative practices that are aligned with firm strategy will have a greater improvement in financial performance at the time of adoption than late strategically unaligned adopters at the time of adoption.

Kennedy and Fiss' study, by utilizing a more direct measure of motivation and finding that the two motivations coexist for both early and late adopters, provided a critical step toward more fully understanding the motivations and consequences of isomorphic adoption. Even so, it stopped short of investigating whether these motives are actually realized. Importantly, however, it provides a strong implication that technical and social gains may not strictly substitute for each other and may even reinforce one another such that higher technical performance enhances legitimacy and vice versa (Kennedy \& Fiss, 2009). Further evidence exists elsewhere in the literature that motivations towards technical and efficiency gains, as well as the gains themselves, are not independent phenomena nor are they temporally constrained to early or late adoption timeframes. In particular, two prior studies provide explanations for why technical and legitimacy gains may positively interact. Rindova and colleagues (Ridova, Pollock, \& Hayward, 2006) find that firms that seek higher levels of social reputation are able to leverage their social standing as a vehicle to increased economic opportunities. Similarly, Kamins and Alpert (2004) demonstrate that firms that succeed in technical innovation and market share leadership experience a boost in social benefits. In each 
case, technical performance and legitimacy are not disjointed in their influence on one another nor do they clearly pertain to any one particular part of the institutional timeline. Moreover, in each case, the influence of one on the other is positive, suggesting that technical and legitimacy benefits enhance one another.

Apple Inc. provides a unique real-life illustration of the interplay between technical performance and legitimacy. Apple has not invented a new product or product category since improving on then current PCs by adding a graphical user interface and a mouse input in 1984. They were not the first to introduce touch screen applications, ultraportable mp3 players, or sleek, user-friendly laptops. They did not provide the most technologically advanced products, nor did Apple begin their wave of success as the firm with the best brand. They, however, excelled in engineering (and marketing) products with technical (and brand/lifestyle) appeal. Despite their lack of standing as either a pioneer or technological groundbreaker, they, in the words of Apple designer Jonathan Ive, "design and make better products" (Lee, 2012). Improving existing technology and "doing it better" than competitors has allowed Apple to become a technical leader, and arguably in turn, bolstered their legitimacy. Consequently, their elite reputation also enables them to pursue more and extract more from their technical endeavors (Bajarin, 2012).

By implication, it stands to reason that, early or late, firms that "do it well" or excel technically can be perceived as a leader and extract social benefits from technical success. And conversely, high levels of social approval can improve the ability and opportunity to excel technically. It is difficult to determine the causality of whether 
branding success led to improved technical performance or whether technical success led to improved branding performance. It seems likely that they have worked in tandem, and that it is the combination of the two that has created such positive organizational outcomes. Firms that are able to perform well technically stand to enhance their legitimacy and vice versa. In other words, adopters of institutions that are also capable of providing a firm with technical benefits will see the two types of benefits enhance one another, and the impact to firm performance will be greater than the sum of the gains in isolation.

Hypothesis 4. Late adopters of innovative practices that are aligned with firm strategy will experience an improvement in financial performance at the time of adoption greater than the sum of the improvements experienced at the time of adoption by early strategically aligned adopters and late strategically unaligned adopters.

The empirical framework predicts that late adopters will receive legitimacy benefits and adopters that are strategically aligned with the adopted practice will receive technical benefits. The final hitherto unaddressed quadrant of this framework is that portion of firms that adopt early and are not strategically aligned with the practice. Such firms will not reasonably expect legitimacy or technical gains through adoption of the new practice because they are not strategically aligned with the practice and the practice has not yet become institutionalized and capable of providing legitimacy. Because such firms will incur the costs of adoption and subsequent implementation without significant benefits they should experience a decline in performance. 
Hypothesis 5. For firms whose strategy is not aligned with an innovative practice and that adopt early, adoption will negatively impact financial performance.

\section{EMPIRICAL CONTEXT: SOCIAL MEDIA}

Social media is a crucial consideration for many business executives (Kietzman, Hermkens, McCarthy, \& Silvestre, 2011) as businesses seek new and more effective ways to not only communicate with, but interact with end consumers. A strong trend has emerged such that collaborative social media projects are becoming the predominant source of information for consumers (Kaplan \& Haenlein, 2010). As early as 2006 it was acknowledged that there is an increase in a preference for 'social authority' wherein the people have become collective experts that receive the greater trust from consumers (Brauer \& Bourhis, 2006) coupled with a decreasing level of trust in overt marketing messages. By $2008,58 \%$ of consumers are reported to most trust product information originating from "people like me" (Edelman Trust Barometer, 2008) with that number rising to $64 \%$ by 2010 (Edelman Trust Barometer, 2010). A separate and more recent figure reported by McKinsey \& Company (Edelman, 2012) shows that $78 \%$ of consumers trust peer recommendations while only $14 \%$ trust advertisements.

Concurrent with this trend towards increasing consumer trust in social media and collective expertise (and concurrent with the equally dramatic rise in usage of social media), is a shift, or at least an additional research focus within social media scholarship on the business aspects of the phenomenon. Most early work focused on the impact to society and to individual users (i.e., Boyd \& Ellison, 2007) of social networking sites 
(SNSs), blogs, content communities (e.g., YouTube, Flickr), and virtual social spaces (e.g., SecondLife). More recently, however, numerous scholars are calling for a greater focus on understanding the immense economic value embedded within social media structures and users (Beer, 2008) and how firms can survive in and exploit the existing and emerging social and corporate environment. The bulk of the response to this call has occurred within the marketing and IT realms (e.g., Carlyon, 2011; Vergeer \& Pelzer, 2009) with other areas such as entrepreneurship (e.g., Fischer \& Reuber, 2011) and organization studies (e.g., Levine \& Prietula, 2011) providing a much sparser offering. Overall, social media has recently been a topic of scholarly attention in a wide variety of areas, ranging from social topics such as adolescent identity formation (Usita, 2011), privacy (Verni, 2012), and suicide prevention (Schicker, 2011), to politics (Chen, 2011), crisis communication (Stirratt, 2011), education (Rodgers, 2012), network and knowledge topics (Eller, 2012; De Choudhury, 2011), fundraising (Grooters, 2011), epidemiology, and various business topics including entrepreneurship (Losapio, 2012), marketing (Carlyon, 2011), and online business strategy (Kumar, 2011). As noted, the rise of interest in social media as a business topic of study is quite recent, but the entire social media arena across all topic areas is still quite new. In a search of dissertations with 'social media' in either the title or abstract, 534 of the 578 hits (93\%) have been published since 2010 and 78\% since 2011 (http://search.proquest.com/pqdt, April 2013). In top management journals only 4 articles have been published (or are forthcoming) that focus on social media and all of them have been since 2011.

In light of the increasing scholarly and corporate attention being turned towards social media, the core proposition is that companies have much to gain from engaging in 
the conversations that consumers are coming to expect in place of the more traditional one-way messages (Kaplan \& Haenlein, 2011). A significant challenge facing companies is the proliferation of social media offerings, including vast possibilities of participating in numerous existing platforms or even developing their own. Similarly, scholars face the analogous challenge of assimilating the existing disparate literatures, classifications, and definitions of social media and related concepts such as the Web 2.0 and user generated content (UGC). To aide in the task of achieving clarity regarding what social media is and how to discuss and research it, I offer a definition and a brief discussion of what social media is not. I also utilize a classification scheme developed by Kaplan and Haenlein (2010) that relies on the theoretical roots of the two components of the phrase 'social media'.

\section{What is Social Media?}

Several terms have been coined and widely (and loosely) used in the realm of social media that deserve discussion in order to provide clarity and differentiation. One popular term is Social networking sites (SNSs). SNSs tend to focus on communicating within already existing social networks (e.g., Facebook) or extending their social network (e.g., LinkedIn, dating websites). Because many of the most popular SNSs deal predominantly with existing networks and do not actually focus on creating new connections, some scholars prefer the term social network sites to deemphasize the relationship initiation aspect, which is normally a feature that is available to users, but not typically the focus of or the differentiating feature of what sets SNSs apart from other forms of computer-mediated communication (Boyd \& Ellison, 2007). More central to the 
uniqueness of SNSs is the ability granted to users to maintain and display their social network (Boyd \& Ellison, 2007). While many types of social media provide the essential functionalities of SNSs, many have different emphases, making SNSs an inadequate term for the broader phenomenon. Social websites is another phrase that has caught on that seeks to claim "both social networking sites and social media sites together" (Kim, Jeong, \& Lee, 2010). This usage is problematic, however, since (a) SNSs are more widely considered a type of social media rather than a mutually exclusive categorization, and (b) for many parties interested in social media, the emphasis is not on the website, or even the internet. Web 2.0 is another popular catch phrase that originated in 1999 and was popularized in 2004 (O'Reilly, 2005) that is used to describe a shift in the way the World Wide Web is utilized as opposed to referring to any actual change in the technical properties of construction or operation. The new web is one where the line between producers and consumers of applications and content is blurred and the most popular and important activities on the web are continuously evolving projects where participation and collaboration have replaced individual publishing and unidirectional communication. Some examples of the Web 2.0 are seen in the Britannica Online being replaced by Wikipedia, personal websites being replaced by blogs, directories (taxonomy) are replaced by tagging ("folksonomy") applications such as Pintrest, and online role-playing games (RPGs) are replaced by massively multiplayer online role-playing games (MMORPGs). While the Web 2.0 is undergirded by various technologies, such as Adobe Flash, it is not in itself a technology or type of web application. It is broader than social media and may be best described as the ideological platform for the emerging uses and preferences of the World Wide Web. User Generated Content (UGC), also called User 
Created Content (UCC) is another term that is related but distinct from social media. Examples of UGCs include photos, poetry, status updates, profiles, and videos. According to the Organisation for Economic Cooperation and Development (OECD, 2007) UGCs must be publicly accessible, exhibit some amount of creative effort, and originate outside of professional routines. UGCs are the ways in which people use social media. With some clarity as to what social media is not, it becomes simpler to define social media itself. I view social media as the set of web-based and mobile technologies and applications that enable participatory communication and collaboration towards the creation and exchange of user-generated content. Notably, this definition acknowledges both the social aspects and media aspects as the two key dimensions of the phenomenon. Predictably, the most recent and widely used classification of social media distinguishes the various types along these two dimensions.

Within this definition of social media there are many types that can be distinguished along a social dimension and a media dimension. The classification of the various types of social media presented by Kaplan and Haenlein (2010) categorizes them along a social dimension and a media dimension and draws upon theories from the fields of media research and from research on social processes. First, in regards to the media side of social media, social presence theory (Short, Williams, \& Christie, 1976) states that media differs in the level of social presence that occurs during the presentation of media. The degree to which the physical senses are stimulated during communication represents high or low social presence. In connection with social presence theory, media richness theory (Daft \& Lengel, 1986) suggests that the overall goal of media exchange is the resolution of ambiguity and uncertainty and that media differ in the amount of 
information that contributes to this purpose. Thus, these two media-oriented theories concurrently suggest that media can have a high sensory and experiential content and also explanatory informational content that together constitute a single dimension of social media. Virtual social worlds such as Second Life are an example of social media high on the Social presence/Media richness scale and microblogs such as Twitter are on the low end. Regarding the social aspect of social media, self-presentation theory (Goffman, 1959) suggests that people seek to control the information made available to others as they interact with the overarching goal being that they are perceived by others in a way consistent with their preferred self-image. The key mechanism by which internet users can control the release of information is through self-disclosure of personal information. Social media vary widely in the amount of personal information that is made available by users and collaborators. For example, personal blogs are high on self-disclosure while Wikipedia is low. In contrast to the first dimension that focuses on the experiential and explanatory impact to the end user, this second dimension focuses more on the disclosure of personal information of the social media originator. Table 1 illustrates the resulting classification model with an example for each category (Kaplan \& Haenlein, 2010).

\section{TABLE 1}

Classification of Social Media by social presence/media richness and self-presentation/self-disclosure

\begin{tabular}{|c|c|c|c|c|}
\hline & \multicolumn{3}{|c|}{ Social presence / Media richness } \\
\hline & & Low & Medium & High \\
\hline $\begin{array}{c}\text { Self- } \\
\text { presentation/ }\end{array}$ & High & Blogs & $\begin{array}{c}\text { Social networking sites } \\
\text { (e.g., Facebook) }\end{array}$ & $\begin{array}{l}\text { Virtual social worlds } \\
\text { (e.g., Second Life) }\end{array}$ \\
\hline $\begin{array}{c}\text { Self- } \\
\text { disclosure }\end{array}$ & Low & $\begin{array}{l}\text { Collaborative projects } \\
\text { (e.g., Wikipedia) }\end{array}$ & $\begin{array}{l}\text { Content communities } \\
\text { (e.g., YouTube) }\end{array}$ & $\begin{array}{c}\text { Virtual game worlds } \\
\text { (e.g., World of Warcraft) }\end{array}$ \\
\hline
\end{tabular}




\section{The Rise of Social Media}

To better grasp the usefulness and appropriateness of studying organizational phenomena within a social media context it is helpful to understand the scale, momentum, and demographics of social media usage. From the founding of the earliest social websites, such as SNSs SixDegrees.com in 1997 and Open Diary in 1998 to the current-day behemoths such as Facebook, Qzone, Twitter, and Youtube, social media has undergone an transformation from obscure to mainstream. The "citizens" of Facebook alone (901 million active users) rival India and China as the world's largest country (Facebook, 2012). Amazingly, Facebook is far from alone in the lofty realm of online social communities with at least 100 million active users, a club that currently boasts 11 such members (http://en.wikipedia.org/wiki/List_of_virtual_communities_with _more_than_100_million_active_users, 2013). The throngs of people that participate in social media are also surprisingly active. An average week near the close of 2011 saw roughly 3,500,000,000 pieces of web content shared each week on Facebook (Mediabistro, 2012a). YouTube had over 1,000,000,000,000 (that's 1 trillion) views in 2011 alone, which equates to almost 140 views for each inhabitant of earth (YouTube, 2012a). YouTube currently has over 800 million monthly users watching 180 million minutes of video watched each month. Twitter's 175 million active users produce 340 million tweets (Twitter, 2012) each day and over 750 million photos were posted on Facebook during the 2010 New Year's Eve weekend alone (Zuckerberg, 2011). The story of the social media movement is also more than just the sheer numbers of participants and massive quantities of UGCs. While young people continue to lead the 
charge, it is the older portions of the population that are recently flocking to social media applications in the largest numbers. For instance, from May 2008 to May 2010 the number of internet users over the age of 35 that use SNSs jumped from $25 \%$ to $61 \%$. During this same time period the 50 to 64 year old group increased from $11 \%$ to $47 \%$ (Mediabistro, 2011). Embedded within this movement is also a dramatic increase in mobile access of social media. With the Mobile Marketing Association of Asia reporting an estimated 4.8 billion mobile phones in use as of 2010, compared to just 4.2 billion toothbrushes (60 Second Marketer, 2011), mobile internet is projected to surpass desktop internet usage by 2014 (Digitalbuzz, 2011). Of those mobile internet users, 91\% of mobile internet time is used for socializing. In fact, the average American in 2010 spent 2.7 hours per day socializing on mobile devices (Digitalbuzz, 2011) and in 2011 55\% of the then 100 million active Twitter users accessed Twitter via mobile devices (Mediabistro, 2012). With so many participants doing so much so frequently, it is not surprising that Social media is an excellent fit to be studied using epidemiological models of infection and diffusion (Lerman, Galstyan, Ver Steeg, \& Hogg, 2011). Indeed, social media seems to easily out do disease epidemics since, as Fisman puts it, "The way that information moves is very similar to the way disease moves" (Garrity, 2011), only information now moves much faster. As an illustration of the impressive speed with which social media mechanisms allow content to spread, consider the comparison of a single YouTube clip to the devastation of a major pandemic in recent history. The bubonic plague, possibly the deadliest pandemic in history took 35 million lives over a period of 3 years beginning in 1348, or roughly 50,000 lives per day. In comparison, in July of 2010, Proctor and Gamble uploaded to YouTube a 30 second video clip entitled 
The Man Your Man Could Smell Like as a promotional vehicle for its Old Spice brand. Within 36 hours the spot was viewed an astounding 23 million times, for an 'infection rate' of 15 million per day. Similarly, in March 2012, a 30 minute clip seeking to popularize the fugitive rebel leader Joseph Kony was uploaded on a Monday and had over 70 million views by Friday, to go along with over 200 new video clips uploaded by others and associated with it as well as over 500,000 comments (Steel, 2012). At rates like these, the entire Black Death pandemic would have lasted no more than a long weekend. While these two examples lacked sustained growth past a few days, other examples such as a video of Susan Boyle singing "I Dreamed a Dream" on the reality TV show Britain's Got Talent not only reached 70 million views in six days, but eventually reached over 480 million views (well short of YouTube's all time most popular video - a song entitle Baby by teen pop sensation Justin Bieber and rapper Ludacris with 757 million views as of July 2012) (YouTube, 2012b). The Twitter version of record-setting explosive information diffusion is pop artist Beyonce's pregnancy announcement during MTV's VMAs that reached a pace of 8,868 Tweets per second (Rao, 2011). A final example of the size, reach, and speed of social media is the political fundraising of Barack Obama in his initial presidential campaign. In January, 2008, he set a new record by raising $\$ 32$ million in a single month, $\$ 28$ million of which was due to online donations by driving traffic to his website with extensive use of Facebook, MySpace, and Twitter (Arrington, 2008). The very next month, Obama did not attend a single fundraising event and managed to raise $\$ 55$ million more through online donations alone, the vast majority of which were small donations (under \$100). In all, an estimated 87\% 
(Peddycord, 2008) of his campaign funds, which totaled \$748 million (Federal Election Committee, 2008) were generated through social media channels.

\section{Social Media from a Business Perspective}

Despite the exponential growth of social media as a communication platform, businesses are not universally excited about using social media for their purposes. Of the companies on the 2011 Fortune 500 list $77 \%$ do not have a corporate blog, $38 \%$ do not have an active Twitter account, and $42 \%$ do not have a corporate Facebook page (Mediabistro, 2012). Some reasons for this lack of interest in something that seemingly everybody is interested in include lack of ROI, lack of ability to determine ROI, legal risks, social risks, security risks, and lack of awareness by the leadership team (Edelman, 2012). With so many identifiable pitfalls and challenges, many executives have chosen to steer clear of the social media experiment for the time being (Edelman, 2012). Of course, where the social media movement is motivated by entertainment, convenience, and socializing for individual participants, fiscally responsible firms are not to be expected to share those same motivations. There are, however, several reasons for profitseeking firms to pursue some form of social media strategy. In fact, a growing number of companies are even employing some version of a social strategist position, with at least $36 \%$ of such positions occurring in upper management (LinkedIn, 2011). So, what are the fundamental motivations of companies to use social media? In order, the top four stated objectives are brand reputation management, driving promotions, customer service management, and risk management (Maleshefski, 2011). These objectives map nicely on to two overarching ways companies use social media: to disseminate information and to 
obtain information. Each of the two high-level objectives will be further developed and illustrated with recent examples of companies that have used social media successfully to achieve these objectives.

First, the top two stated company social media objectives, branding and driving promotions, indicate that companies believe that social media platforms are a valid place for companies to disseminate information to consumers. This belief seems to be justified. $57 \%$ of respondents to a 2011 survey (Mashable, 2011) said they 'Like' a brand on Facebook specifically because they want to receive information regarding discounts and promotions. Consumers seek also seek product specific information through social media channels. While many consumers have made purchases online for some time, they also research products online more than ever before. Not only that, but they are also more likely to buy from brands with which they interact in social media spaces. A recent survey determined that $81 \%$ of U.S. smartphone and tablet owners research products online and $41 \%$ make purchases online (eMarketer, 2011). Of consumers that make purchases online $43 \%$ of them are social media "fans" or "followers" of the brands or products that they buy (Rayfield, 2011). Recent research within the Restaurant industry suggests that customers that interact with Restaurants through Twitter, Facebook, Foursquare, UrbanSpoon, and other websites are not only the customers that dine out more often but are also more likely to become repeat customers (National Restaurant Association, 2011). With trends like these it is not surprising that annual expenditures of advertising in online spaces has increased from $8.7 \%$ of total media advertising in 2008 to $11.2 \%$ in 2010 , with that figure projected to grow to $15.2 \%$ by 2013 . The strategic 
shift towards online marketing seems justified in light of the shift towards online research and purchasing. It is notable that this shift is on a large scale across all demographics, as evidenced by the finding that $62 \%$ of all consumers in the U.S. had read a product review online at websites such as expert blogs, SNSs, and shopping sites in the last six months (Lightspeed Research, 2011).

One successful example of a company using social media to disseminate information is specialty blender manufacturer Blendtec's series of quirky and fun "Will It Blend?" videos. In these inexpensive videos everything from golf balls, a "cochicken" (Coke and a rotisserie chicken), a hockey stick, and a Bic lighter, to an iPhone, marbles, and cubic zirconia are tested to see if they will blend, typically with an impressive end result of little more than slush, mush, or dust (Briggs, 2009). Viewers are invited to participate by sending in requests for founder Tom Dickson to blend in the next episode. Since the campaign began in 2006 Blendtec has increased sales more than 700\%, and has done demonstrations on numerous television shows such as The Tonight Show with Jay Leno and NBC's Today where host Meredith Vieira was served a boneless version of the “cochicken” (King, 2007). They sell Will it Blend? merchandise, spoof major events such as the Super Bowl by blending mini helmets of the participating teams, and if you hurry you might even be able to join their contests to win a new iPhone $4 \mathrm{~S}$ with a paid two-year contract and the pleasure of seeing Dickson blend your old iPhone 4. As of July 2012, the total YouTube views had reached 196 million, or about double the number of viewers of a typical Super Bowl (YouTube, 2012c). 
The second reason for companies to engage in social media, one that is more aligned with the third and fourth most popular social media objectives, customer service and risk management, is to obtain information. While customer service and risk management are both much more complex than simple information gathering, they both entail strong elements of information flowing from external sources towards the company in forms such as complaints, brand perceptions, policy opinions, product preferences, and innovative ideas. While this is not the most prolific type of information flow on social media applications $17 \%$ of consumers that interact with brands on Facebook do so by sharing experiences and stories about the brand (Mashable, 2011). Considering that companies such as Nike, Burberry, Levi's, and Starbucks have followers numbering in the millions (Facebook, 2012), that equates to a massive incoming information flow. In support of this notion, a reported $62 \%$ of consumers have already used social media for customer service issues with $76 \%$ saying that they are likely to do so in the future (Maleshefski, 2011). This dynamic, unsurprisingly, varies according to industry. Retail (45\%), Telephone (35\%), Hospitality and Travel (34\%), Cable (33\%), and Banking (31\%) are the 5 industries that the most people report having contacted through social media for support. For these industries and others, the opportunity to learn about customer tastes, positive and negative experiences, and ideas can provide valuable information in managing risks and formulating and implementing strategic endeavors.

Starbucks's my Starbucks Idea program is one example of a company gathering useful information through social media channels (Facebook, Twitter, YouTube, AddThis, and their standalone website). This program began in 2008 and generated 
70,000 ideas in the first year alone and has been called the "poster child" of corporate social media success (SocialMedia.org, 2009). Participants can submit ideas, search for ideas posted by others, and vote for their favorites with the promise that the most popular ideas will be thoughtfully considered by top management (Starbucks, 2012). While only a seemingly minute $0.03 \%$ of the first year's suggestions have become reality ( 25 implemented), they are actually implementing customer ideas, which seems to be resonating very strongly with customers. As evidence of this, Starbucks, with 30 million followers, is currently the second most popular brand on Facebook, second only to CocaCola with 42 million followers (Facebook, 2012). As of March 2012 Starbucks has implemented 202 ideas, with the most recent one being "Mobile Payment at Drive-thru" and the all-time most popular one being "Buy 10 get 1 free!" (Starbucks, 2012).

\section{DATA AND METHODS}

Publicly traded U.S. manufacturers of clothing, accessories, shoes, jewelry, health and beauty aids, and toys and their adoption of social media were investigated in this study. This empirical context has two important advantages. First, there are many firms in these industries that have Facebook, Twitter, and YouTube accounts along with sufficient evidence that these practices have become expected and taken-for-granted. Evidence of this expectation can be observed with a casual browsing of the Facebook pages of companies from an industry list such as the one found on apparelnews.net. In addition, the pages of recent adopters are marked by comments near their "joined 
Facebook" dates, from both followers and companies alike that indicate that it is "about time" that they "finally joined Facebook" and that they are "entering the $21^{\text {st }}$ century like everybody else." Furthermore, popular media articles frequently express amazement that even manufacturing or industrial companies would consider not utilizing social media (i.e. Reed, 2010).

To further validate that the adoption of social media among US manufacturers is an institutional process, I conducted several interviews with managers within sample industries that were part of or that were familiar with the decision to adopt social media. I also gathered additional interviews of relevant CEOs and other executive officers conducted during the years 2008 to 2011 by popular press and media professionals in order to analyze them alongside the original interviews conducted by myself. I used the data gathered from the interviews to ascertain whether and to what degree legitimacy is a significant motive driving social media adoption. Haveman and David consider legitimacy to be a defining element of institutional processes (2008) and care must be taken to determine that the meanings and motives behind adoption are indeed indicative of institutional phenomena. Specifically, the interviews were instrumental in determining that the diffusion of social media use among US manufacturers is more than simply a rational act of vicarious learning and that it is done, in part at least, out of a belief that doing so will provide legitimacy.

Second, this empirical context is advantageous because there is clear strategic alignment with social media for some, but not all of the firms in these industries. The basic functionalities of externally focused corporate social media are information flow 
and informative collaboration between the company and consumers. In fact, the top four stated objectives of using social media are brand reputation management, driving promotions, customer service management, and risk management (Maleshefski, 2011). These objectives map nicely on to two overarching ways companies use social media: to disseminate information and to obtain information. Firms that employ a moderate to high degree of a differentiation strategy (Porter, 1980), but not those that do so to a very highly degree, are able to benefit from social media because they are more likely to benefit from product information dissemination and from information gathering through participating in social media. A differentiation strategy, generally, is highly aligned with the use of social media. However, it is important to note that this general proposition will not apply in circumstances where customers reject social media as an acceptable avenue for advertising, purchasing, customer service, or other types of interaction with manufacturers or vendors. To this point, recent research has found that consumers of luxury goods do not consider online storefronts, impersonal sales pitches, or information exchange across social media platforms to be acceptable (Morphy, 2012) because the instore shopping experience is an essential component of the value proposition (Doran, 2013). Because luxury goods consumers consider social media to be too pedestrian, much of the following arguments that explain the alignment of social media and a differentiation strategy will not apply to firms that employ a very high level of differentiation.

The alignment between a differentiation strategy and the use of social media is rooted in the fact that their key success driver is the creation of a high perceived value in the 
minds of consumers. A differentiation strategy focuses on value and does so generally by providing unique features that increase the desirability of the product in the eyes of the customer so they will be willing to pay a higher price. While not universal, firms that do little or nothing to differentiate themselves or their products often employ a cost leadership strategy. This strategy seeks to reduce their costs below those of competitors. They seek to provide consumers with an adequate product for the lowest price by optimizing each activity within the value chain. While neither strategy entirely ignores either customer value or costs of production, differentiators focus on providing value to the customer and cost leaders focus on reducing their costs. Consequently, the drivers of strategic success differ greatly between the two generic strategies. For the differentiator, an ideal strategic position depends on managing the perceived value of the product, mainly through product feature offerings, branding, and customer service. For the low cost provider, an ideal strategic position is mainly dependent upon managing the cost of inputs, operational efficiency, and economies of scale.

Social media provides all firms a method for disseminating information to consumers. However, this is only strategically aligned with moderate to high differentiators because their core strategic goals of providing unique product features and branding function largely through the exchange of information. Social media provides them an additional (and acceptable) channel for advertising distinctive product features and establishing or maintaining a unique brand identity. Indeed, the dominant logic of modern marketing, which these processes largely fall under, is the notion that marketing is a continuous social and economic process (Vargo \& Lusch, 2004). In short, differentiators rely on 
information flow and social processes to execute their strategy. This use of social media is not strategically aligned with cost leaders because it is not likely to be useful towards achieving their core strategic goal of reducing costs. Cost leaders, in contrast to differentiators, often avoid marketing costs and have few or no sales to promote because the margins on their products are too small to offer special discounts.

Social media also provides firms a way to gather information from customers in the form of customer opinions, complaints, and innovative ideas. Again, this functionality of social media is strategically aligned with the core goal of differentiators but is not aligned with the core goal of cost leaders. Differentiators can use social media as a way to increase value to customers through focusing on customer service and responsiveness. In addition, differentiators can gather useful information from consumers by using social media as Starbucks has done through their "My Starbucks" initiative. Cost leaders are not constrained from seeking useful feedback from consumers; however, it seems unlikely that customer feedback through social media channels will relate to their core strategic focus and help them streamline the assembly line, identify a cheaper supplier, or invent a process that creates less waste.

\section{Sample}

The sample of firms used for data analysis includes publicly traded US firms registered under the NAICS codes in Table 2 that use Facebook, Twitter, or YouTube, considered the cornerstones of most social media strategies (Vollmer \& Premo, 2012), and were identified using the Compustat database. Because Facebook did not begin 
allowing corporate pages free of charge until 2007 and Twitter was not launched until late 2006, firms that began using Facebook, Twitter, or YouTube from 2007 to 2011 will be included in the sample. For those years, I identified 250 public firms for those industries within those years. Using company websites, annual statements, analyst reports, and trade reports, I then generated a list of the brands owned by each firm. Companies that did not own any brands (e.g. manufacturers that sell only private label) or that sold only or a strong majority of products of brands owned by other companies (e.g. pure retailers) were excluded from the sample because these firms fall outside the theoretical arguments about strategic alignment, resulting in 159 firms. Firms were then identified as users of Facebook, Twitter, and YouTube by using the company name (and popular variants) as search terms within the search functionalities provided by each of the three websites. Only those pages clearly identifiable as official company pages were included while fan pages and interest groups were excluded. To aid in identifying company pages and in gathering explanatory and control variables from Facebook, Twitter, and YouTube, a web-based software tool was developed for each of the three social media websites that communicates with the application programming interfaces (APIs) of each website and that is capable of extracting data from the company pages. A web scraper was also developed to gather additional information that was not available through the APIs. The final step was to exclude firms that had no social media use during the sample years as well as firms that did have social media use, but, due to timing or data availability, were lacking complete data for at least 4 quarters before and after their initial adoption of social media practices. The resulting sample included 120 firms 
that used at least one of the 3 types of social media and that had sufficient data to be included in the testing of one or more hypothesis.

TABLE 2

List of Industries in Sample

\begin{tabular}{cl}
\hline NAICS Code & \multicolumn{1}{c}{ Description } \\
\hline 315990 & Apparel Accessories and Other Apparel Manufacturing \\
316992 & Women's Handbag and Purse Manufacturing \\
325611 & Soap and Other Detergent Manufacturing \\
325620 & Toilet Preparation Manufacturing \\
339910 & Jewelry and Silverware Manufacturing \\
339930 & Doll, Toy, and Game Manufacturing \\
446120 & Cosmetics, Beauty Supplies, and Perfume Stores \\
446199 & All Other Health and Personal Care Stores \\
448310 & Jewelry Stores \\
451110 & Sporting Goods Stores \\
451120 & Hobby, Toy, and Game Stores \\
\hline
\end{tabular}

\section{Variables}

Dependent variable. Since the implementation of new practices often requires some degree of capital or resource investment, the accounting-based period profitability measures may not reflect the full potential for economic improvement for the accounting period during which any one-time adoption and implementation costs occurred. In this way, the first accounting period subsequent to adoption implementation is uniquely burdened with one-time costs that may mask any perpetual profitability improvements. Additionally, many new practices involve a learning curve where efficiency of the practice improves as the organization learns how to minimize the costs and maximize the benefits of the practice. In each case, the long-term economic impact to a firm is unlikely to be clearly evident precisely at the point in time of adoption, but may become clearer in subsequent reporting periods. Conversely, increased profitability due to technical 
improvements may not be reflected in too distant reporting periods. While the actual technical gains may remain, they may appear to be short lived and erode over time as other firms adopt and the profitability increase caused by adoption is competed away. This detail is helpful in noting that a lagged performance measure will become a less relevant assessment of the impact of an innovation adoption event the greater the lag. Thus, I use the change in ROA from the year during which adoption occurred $(\mathrm{t}=0)$ to year after the adoption event $(t=1)$. Because adoption may occur any time from the first to the twelfth month of an annual accounting period, ROA at $t=0$ was calculated as the combined ROA of the quarter during which adoption occurred and the 3 quarters directly preceding it, and the $t=1 \mathrm{ROA}$ as the combined ROA of the 4 quarters after the quarter during which adoption occurred.

To control for macroeconomic variations across years, and because recessions, like the one experienced during the timeframe of this study, might influence firms differently depending on their strategic focus (low cost providers might benefit while differentiators suffer), I adjusted all quarterly ROAs using the ROAs of Dow Jones Industrial Average (DJIA) firms. ROAs were adjusted by subtracting the quarterly ROAs of those firms from among the portion of DJIA firms that most closely matched their degree of differentiation, resulting in a relative ROA that reflects quarter to quarter and year to year financial performance relative to the portion of the market that employs comparable strategies and that is, thus, most likely to be influenced by a recession or boom in comparable ways. Using a market adjusted ROA provides three important advantages over simply including dummy variables for year of adoption in the statistical models as a 
way to control for variation in overall market conditions. First, year dummies would mistakenly assume that the types of firms that adopt in a given year are not qualitatively different from year to year in any way that would confound with key variables (e.g. more strategically aligned firms adopt in 2008 than in 2011). Second, additional variables reduce the power of statistical models. Third, it allows for differences in how a recession might impact firms based on strategic orientation to be taken into consideration.

Change in relative ROA was calculated as the relative ROA of the 4 quarters after adoption minus the relative ROA of the 4 quarters preceding. Since firms can adopt Facebook, Twitter, and YouTube at different times, change in relative ROA is calculated four separate times, once for each of the individual social media types, and once for the combined social media model.

Independent variables. Adoption timing was dummy coded with early adopters as 1 and late adopters as 0. Each Facebook, Twitter and YouTube account has an official start or joined date associated with their page. However, new accounts do not automatically show in search results until some form of content has been posted. Furthermore, even once marginal amounts or types of content have been posted, social media users are likely to ignore Facebook, Twitter, and YouTube accounts with infrequent or irrelevant content. To account for this, various minimum initial activity rates were assessed as benchmarks for effective adoption so as to include the majority of the data, but still strict enough that there is a distinction between account creation and account usage. Thus, to signal that the social media accounts are active, effective adoption date for Facebook is the first month during which at least 4 company-generated posts of any type occur. Using 
this benchmark, $71 \%$ of Facebook pages are considered active in their first month after creation, but within six months that number was 93\%. For Twitter, effective adoption date is the first month with at least 10 tweets. Using this benchmark, only $42 \%$ of Twitter accounts were considered active in their first month after creation, but within six months that number was $82 \%$. For YouTube, effective adoption date is the month during which the first video was uploaded. With this benchmark, 56\% of YouTube accounts were considered active within their first month, and within six months $89 \%$ were considered active. Following others in the literature (Westphal Gulati \& Shortell, 1997; Kennedy \& Fiss, 2009), the temporal dichotomy of early and late adopters was determined by dividing them into two groups at roughly the midpoint of the observed adoption time period. Because a given firm may be an early adopter for one social media platform and late on another, the temporal dichotomy was determined 4 times, once using the effective adoption dates of each of the 3 social media types, and a once for a firm's earliest of the 3 effective adoption dates. Thus, each firm has 4 adoption dates and 4 adoption timing dummy variables. A third category for very early adopters is not relevant to this study because social media practices have not existed for very many years, negating the need for a third grouping as some have utilized in the past.

Strategic alignment is dependent upon a firm's degree of differentiation. Three expert judges separately rated each sample firm on a scale of 1 to 5 to denote the degree to which their products and services are differentiated. Expert judges were instructed and trained as outlined in Appendix A as to how to rate each firm using a two-pronged approach that considers both stated and observed strategy. The average rating was 3.26 
and the average pairwise correlation of the expert judges was $.84(.85, .85$, and .82$)$. Firms that were at least moderately differentiated might reasonably be considered to be strategically aligned with the adoption and implementation of actions, such as social media, that promote the desirability of their product offerings. However, firms that are very highly differentiated, such as Coach, Incabag, and Tiffany and Co., might not be well aligned strategically with the use of social media. Consumers of luxury goods consider the in-store shopping experience to be an essential element of the brand's value proposition (Doran, 2013). Luxury goods consumers want to try things on, interact with product experts, and hold or touch the product (Doran, 2013). Social media and online stores, in fact, are considered by most people, as recently as 2010 , to be too pedestrian for luxury brands (Morphy, 2012). To account for this, only firms with an average rating between 3 and 4.33, inclusive were coded as strategically aligned.

Control variables. In addition to the main independent variables, I included several environmental and firm-specific control variables to rule out alternative explanations of adoption benefits. Implementation effort has been identified as one reason late adopters may fail to achieve technical gains (Westphal, Gulati, \& Shortell, 1997). In fact, some late adopters may even unequivocally avoid investing significant resources in order to reduce or eliminate the costs of adoption (Westphal \& Zajac, 1994). I therefore control for implementation effort by capturing the frequency of company-generated posts, comments, and other activity. Activity rate is measured as the log of the number of company-generated posts per month for the first year after adoption, and is measured for Facebook, Twitter, YouTube, and all of them combined. A The second control for 
implementation quality is the number of accounts, measured as the log of the number of Facebook pages, the log of the number of Twitter accounts, the log of the number of YouTube channels, and the log of the number of the combined amount. The third control variable for implementation quality is types, measured as the number of the 3 main social media tools they use. The technical benefits of adopting social media may change over time as the number of consumers that use social media increases. Because this has the potential to explain why late adopters may expect larger technical gains than early adopters and hence why some firms chose not to adopt early on but chose to adopt later, I will control for the number of active users of Facebook, Twitter, and YouTube at time of adoption for the lagged regression models and each quarter in the time series models. All three social media sites define active users as those that $\log$ in at least once a month. Company size has been shown to influence profitability (Sharfman, Wolf, Chase, \& Tansik, 1988), flexibility in responding to environmental influences (Dean, Brown, \& Bamford, 1998), and visibility to external constituencies, and hence susceptibility to the institutional environment (Edelman, 1990). This will be measured as the log of total assets at the time of adoption in the lagged regression models and each quarter in the fixed effects models. Industry dummy variables were also used to account for industryspecific attributes that may influence the benefits of adopting social media practices.

\section{Preliminary Analysis}

The first phase of data analysis was to conduct or gather, and then examine the interviews of managers involved in social media adoption decisions. In these interviews I sought for evidence regarding the institutionalization of social media adoption, including 
whether doing so was considered necessary due to external social pressures, due to being an obvious or taken for granted practice, and whether they believed adoption would result in legitimacy. I also sought to learn what other reasons they had for adopting and the timeframe of when these beliefs and motives emerged. This initial stage of analysis was critical to establish that the adoption of social media in these industries is indeed an institutional process as opposed to simply rational economic decision making or organizational learning (Mizruchi \& Fein, 1999).

Six original interviews were conducted and recorded by phone or online messaging platforms. These individuals represented several industries including retail clothing, accessories, toys, as well as conglomerate corporations that included financial services and branded food products. Two of the six individuals also consulted as social media experts on behalf of their employers and had extensive experience in dealing with the social media decision making of top management teams across a number of industries.

Five additional interviews conducted between the years 2008 to 2011 by media professionals were gathered from industry relevant trade publications, corporate websites, and professional blogs. In each of these, the individual interviewed was either a senior VP level employee that specialized in social media or a CEO that had been highly involved in the decision to begin using social media. Only past interviews that addressed at least some key questions regarding the motives and reasons (and their emergence) for adopting social media practices were utilized. 
Live interviews ranged from 11 to 21 minutes in length and text or reported interviews ranged from 400 to 3000 words in length. All eleven interviews were found to contain specific language about the technical benefits of adopting social media.

Frequently mentioned items included spreading their message or telling their story, gaining new customers, better serving existing customers, managing negative media, driving traffic to their website, social listening, and extending their brands. All six original interviews and nine of the eleven total interviews also included specific language indicative of institutional pressures as reasons or motives for the adoption of social media. Stated reasons for adoption that fall within this category included keeping up with industry competitors, avoiding alienating expectant customers, getting with the times, showing the progressiveness of their brands, and seeking to appear tech-savvy. Interestingly, multiple interviews also revealed that the mindset to adopt social media for institutional conformance motives was especially strong among older executives. As one interviewee that works for one of the world's largest technology companies as a social media consultant to various retail industries stated:

There is some trying to play catch up and look the part, especially amongst the older people in the company that don't feel like they understand it at all and that don't use social media. Some of them you could tell would just go by, you know, a gut feel that, "if we're the only ones that aren't doing this I don't want to be the one that's out of touch, behind the times. Let's just get some young people that understand this area and let's have them figure it out and do something so that we're not falling behind the rest of the world." There's definitely some of this... Younger people were constantly pushing them in this direction. But the older people, if they don't understand it really, it's a little more dangerous because they feel like, "oh, let's just make a Twitter account or a Facebook page just because, you know, maybe we need to do something." So there were several people like that that didn't really understand what to do or how to 
do it but thought that maybe we should do it if that's what everyone's doing. (Social Media Consultant, September 2012)

While not all interviews revealed such a vivid dramatization of isomorphic adoption at work, the majority of them strongly suggested that such pressures existed and played a significant role in their decisions to adopt social media.

\section{Estimation Methods}

Each hypothesis was tested with 4 models: Facebook only, Twitter only, and YouTube only models, and a combined model. The combined model used control variables that were aggregated across the three types of social media (activity rate, accounts, and active users). Hypotheses 1 (strategic alignment), Hypothesis 2 (adoption timing), and Hypothesis 4 (strategically aligned late adopters) are, empirically, two main effects and their interaction. Hypothesis 3 tests the additivity of the two main effects. Hypothesis 5 test what amounts to the absence of the main effects. All hypotheses were tested using lagged regression models. Lagged regression is ideal because I sought to test how strategic alignment and adoption timing impacted the change in performance from before to after the adoption event. This also allows for the comparison of groups of firms through use of the ANCOVA analogs of the lagged regression models. In fact, for Hypotheses $3 \mathrm{a}$ and $3 \mathrm{~b}$, post hoc contrasts ${ }^{1}$ of the covariate adjusted cell means from the ANCOVA versions of the models were used as the formal test. The comparisons were between quadrants III and II for Hypothesis 3a and quadrants III and IV for Hypothesis 3b. In the case of Hypothesis 5 where there is no variation in the independent variables

\footnotetext{
${ }^{1}$ Post hoc contrasts were done using the ANOVALATOR subroutine available for use within STATA.
} 
and where comparison of groups is not possible, post hoc contrasts were also used, but the test compared the adjusted cell means to zero.

Variables were tested for normality using the Shapiro-Wilk test, and 3 were found to be significantly improved using log transformations: company size, activity rate, and number of accounts. Models were run with and without these variables undergoing the $\log$ transformation. Models with the untransformed variables produced lower model significance overall, but led to no material differences to the overall pattern of results. Because many pairwise correlations among control variables were relatively high I checked the variance inflation factors on each model and all were found to be within acceptable ranges (all below 3.2). Models were also run with and without industry controls. Their inclusion led to slightly lower model significance overall, but led to no material differences to the overall pattern of results, and they are excluded in the reported models.

\section{RESULTS}

Means, standard deviations, and pairwise correlations of variables used in the combined social media lagged regression and equivalent ANCOVA models are displayed in Table 3. Tables 4, 5, and 6 contain the same statistics for the Facebook only, Twitter only, and YouTube only regression and equivalent ANCOVA models, respectively. Table 7 displays the covariate adjusted cell means (predictive margins) and number of 
observations for each category of the combined social media, Facebook only, Twitter

only, and YouTube only ANCOVA models, respectively.

TABLE 3

Descriptive Statistics and Correlations (Combined Models)

\begin{tabular}{|c|c|c|c|c|c|c|c|c|c|c|c|c|}
\hline Variable & Obs & Mean & SD & 1 & 2 & 3 & 4 & 5 & 6 & 7 & 8 & 9 \\
\hline $1 \mathrm{ROA}$ & 120 & .02 & .19 & 1 & & & & & & & & \\
\hline 2 change in relative $\mathrm{ROA}$ & 120 & .01 & .17 & $-.25 * *$ & 1 & & & & & & & \\
\hline 3 strategic alignment & 120 & .54 & .50 & $-.20^{*}$ & .15 & 1 & & & & & & \\
\hline 4 adoption timing & 120 & .51 & .50 & $-.31 * *$ & $.15 \dagger$ & -.07 & 1 & & & & & \\
\hline 5 company size & 120 & 2.67 & .86 & $.33 * *$ & .12 & -.02 & $-.42 * *$ & 1 & & & & \\
\hline 6 accounts & 120 & .65 & .27 & .02 & .09 & -.13 & .14 & $.34 * *$ & 1 & & & \\
\hline 7 types & 120 & 2.02 & .78 & -.09 & $.18 \dagger$ & -.09 & $.19^{*}$ & .15 & $.65^{* *}$ & 1 & & \\
\hline 8 activity rate & 120 & 1.51 & .85 & $-.28 * *$ & .13 & $-.15 \dagger$ & $.56^{* *}$ & -.05 & $.62 * *$ & $.65^{* *}$ & 1 & \\
\hline 9 active users & 120 & 577.50 & 329.15 & $-.25^{* *}$ & $.17 \dagger$ & -.07 & $.60 * *$ & $-.20^{*}$ & $.34 * *$ & $.62 * *$ & $.69^{* *}$ & 1 \\
\hline
\end{tabular}

TABLE 4

Descriptive Statistics and Correlations (Facebook Models)

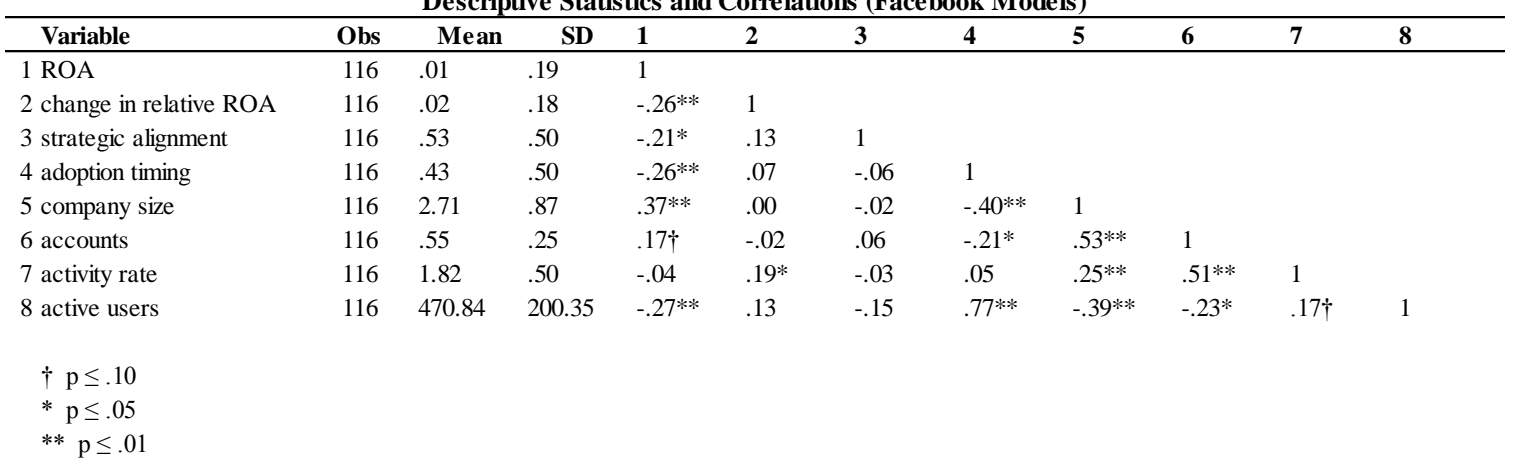

TABLE 5

\begin{tabular}{|c|c|c|c|c|c|c|c|c|c|c|c|}
\hline \multicolumn{12}{|c|}{ Descriptive Statistics and Correlations (Twitter Models) } \\
\hline Variable & Obs & Mean & SD & 1 & 2 & 3 & 4 & 5 & 6 & 7 & 8 \\
\hline $1 \mathrm{ROA}$ & 112 & .03 & .17 & 1 & & & & & & & \\
\hline 2 change in relative $\mathrm{ROA}$ & 112 & .03 & .13 & $-.43^{* *}$ & 1 & & & & & & \\
\hline 3 strategic alignment & 112 & .54 & .50 & $-.30^{* *}$ & $.20^{*}$ & 1 & & & & & \\
\hline 4 adoption timing & 112 & .50 & .50 & -.11 & .02 & -.05 & 1 & & & & \\
\hline 5 company size & 112 & 2.75 & .83 & $.25^{* *}$ & -.12 & -.09 & $-.26^{* * *}$ & 1 & & & \\
\hline 6 accounts & 112 & .62 & .34 & $.22 *$ & .03 & .03 & $-.34 * *$ & $.41 * *$ & 1 & & \\
\hline 7 activity rate & 112 & 2.01 & .67 & .01 & .01 & .05 & .03 & $.38^{* * *}$ & $.51^{* *}$ & 1 & \\
\hline 8 active users & 112 & 74.69 & 42.68 & -.07 & -.12 & .08 & $.70 * *$ & $-.24 *$ & $-.34 * *$ & .11 & 1 \\
\hline \multicolumn{12}{|l|}{$+p \leq .10$} \\
\hline$* p \leq .05$ & & & & & & & & & & & \\
\hline$* * p \leq .01$ & & & & & & & & & & & \\
\hline
\end{tabular}


TABLE 6

Descriptive Statistics and Correlations (YouTube Models)

\begin{tabular}{|c|c|c|c|c|c|c|c|c|c|c|c|}
\hline Variable & Obs & Mean & SD & 1 & 2 & 3 & 4 & 5 & 6 & 7 & 8 \\
\hline $1 \mathrm{ROA}$ & 103 & .03 & .17 & 1 & & & & & & & \\
\hline 2 change in relative $\mathrm{ROA}$ & 103 & .02 & .15 & $-.38 * *$ & 1 & & & & & & \\
\hline 3 strategic alignment & 103 & .54 & .50 & $-.32 * *$ & $.18 \dagger$ & 1 & & & & & \\
\hline 4 adoption timing & 103 & .42 & .50 & -.15 & -.12 & -.13 & 1 & & & & \\
\hline 5 company size & 103 & 2.79 & .76 & $.19 \dagger$ & .08 & -.12 & $-.45 * *$ & 1 & & & \\
\hline 6 accounts & 103 & .43 & .17 & .15 & .03 & $-.18 \dagger$ & $-.24 *$ & $.43^{* *}$ & 1 & & \\
\hline 7 activity rate & 103 & .45 & .47 & -.11 & .16 & $-.19 \dagger$ & $.24^{*}$ & .02 & $.33 * *$ & 1 & \\
\hline 8 active users & 103 & 392.61 & 162.10 & $-.18 \dagger$ & -.03 & -.14 & $.86^{* *}$ & $-.42 * *$ & -.15 & $.35^{* *}$ & 1 \\
\hline \multicolumn{11}{|l|}{$\dagger \mathrm{p} \leq .10$} & \\
\hline$* * \mathrm{p} \leq .01$ & & & & & & & & & & & \\
\hline
\end{tabular}

TABLE 7

Covariate Adjusted Cell Means, ANCOVA Analogs of Lagged Regression Models

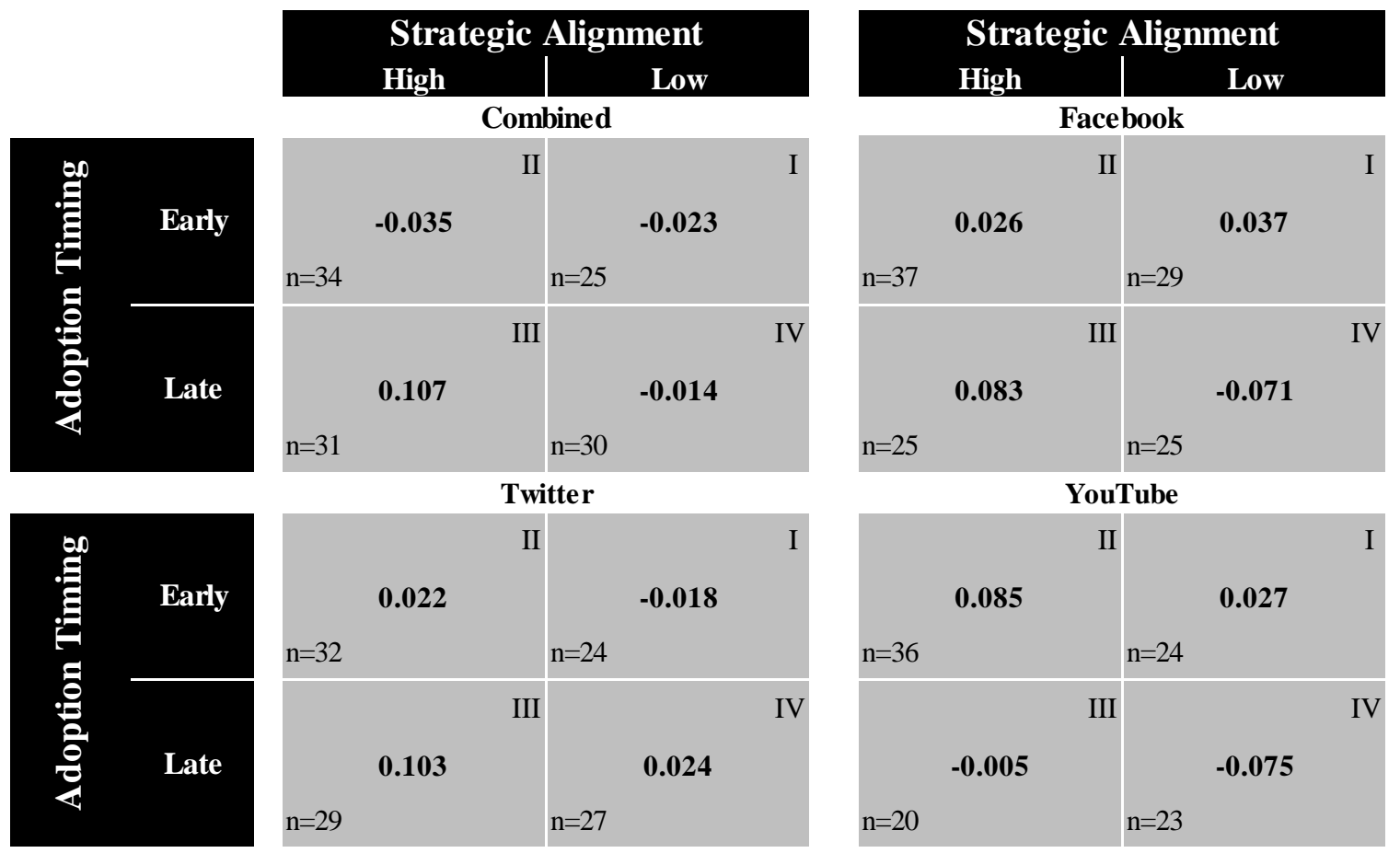

Hypothesis 1 predicted that technical gains will accrue to strategically aligned adopters of social media practices. This was tested using lagged regression models and results are found in Table 8 . The coefficients for the strategic alignment variables used for the tests of Hypothesis 1 are found in models 2, 5, 8, and 11 for the combined ( $\mathrm{p}<$ 
$.05)$, Facebook ( $\mathrm{p}<.05)$, Twitter $(\mathrm{p}<.01)$, and YouTube models $(\mathrm{p}<.05)$, respectively.

In strong support of my contention that strategic alignment is positively related to improved financial performance shortly after adoption, in each case, strategic alignment was significantly predictive of improvement in relative ROA.

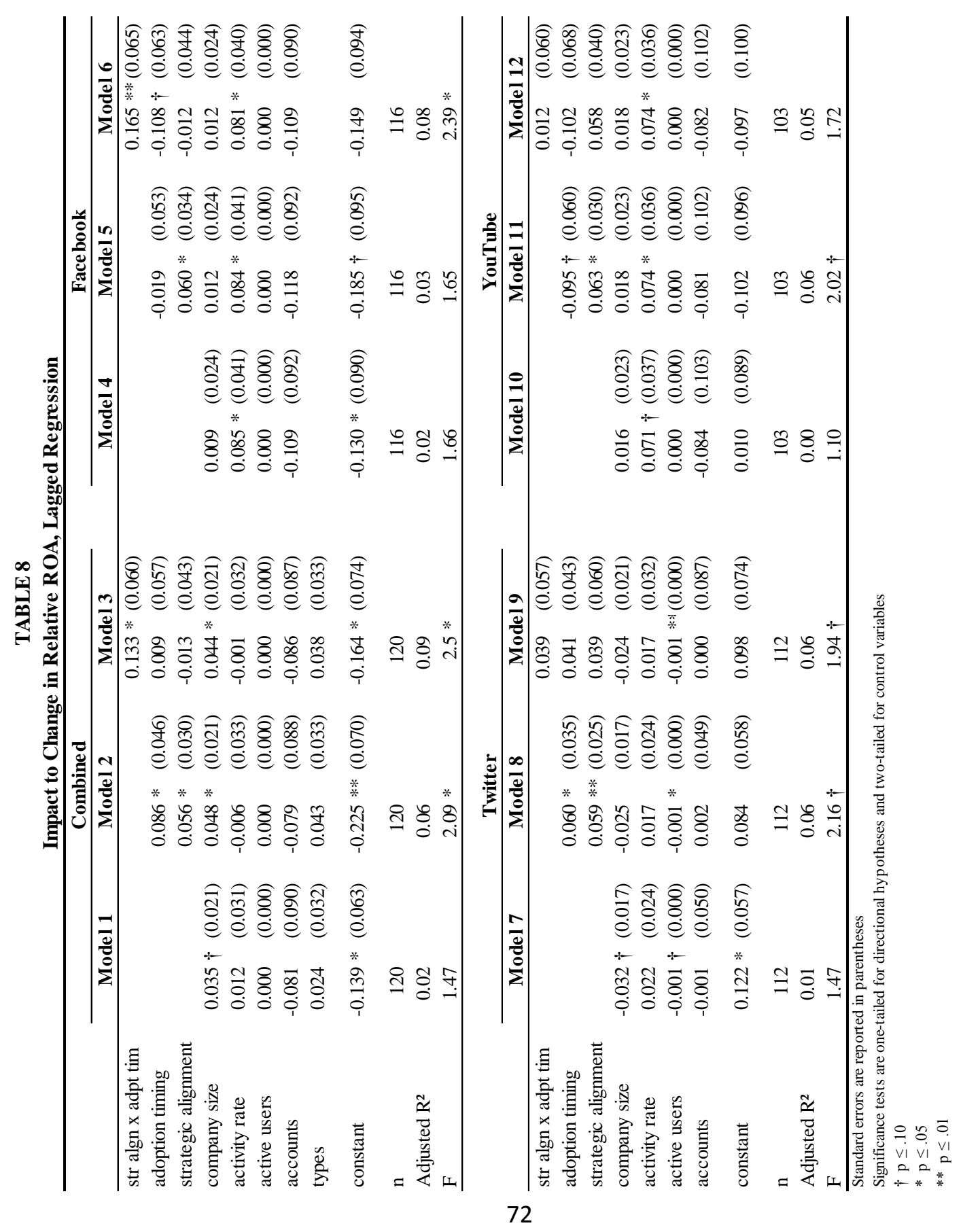


Hypothesis 2 predicted that late adopters of social media would also see an improvement in financial performance, but in this case due to the legitimacy benefits of adopting an institution. Results are found in Table 8. Coefficients for adoption timing (in models 2, 5, 8, and 11) were significant and in the predicted direction in the combined $(\mathrm{p}<.05)$ and Twitter models $(\mathrm{p}<.05)$. The adoption timing coefficient was marginally significant, but contrary to the predicted direction in the YouTube model $(\mathrm{p}<.1)$. Support for Hypothesis 2 is somewhat mixed, but there is still substantial evidence to suggest that adoption of at least certain types of social media provides firms with legitimacy benefits that extend to financial performance.

Hypothesis 3 predicted that technical and legitimacy gains are at least partially additive, or that firms are capable of achieving at least some of both as opposed to just one or the other. In that case, the financial improvement of strategically aligned late adopters (quadrant III) should be greater than that of strategically aligned early adopters (quadrant II) and also greater than that of strategically unaligned late adopters (quadrant IV). Post hoc contrasts were conducted to test this hypothesis using ANCOVA analogs of the four lagged regression models. Hypothesis 3 a specifically predicts that firms in quadrant III will experience greater financial improvement than those in quadrant II. This was supported in the combined social media $(\mathrm{p}<.01)$ and Twitter $(\mathrm{p}<.05)$ models, but not in the Facebook ( $p>$.1) or YouTube ( $\mathrm{p}<.1$, opposite of prediction) models. Thus, I have substantial, but not unanimous support for Hypothesis 3a across the four models. 
Hypothesis $3 \mathrm{~b}$ specifically predicts that strategically aligned late adopters (quadrant III) will experience greater financial improvement than late adopters that are not strategically aligned (quadrant IV). This hypothesis was well supported by the contrasts from the ANCOVA models with the combined $(\mathrm{p}<.01)$, Facebook $(\mathrm{p}<.01)$, and Twitter $(\mathrm{p}<.05)$ models all yielding a significant result in the predicted direction and the YouTube model $(\mathrm{p}<.1)$ resulting in marginal significance. Thus I have strong support for Hypothesis $3 \mathrm{~b}$ suggesting that, among late adopters, those that were strategically aligned with social media achieved greater performance improvements than those that were not.

My fourth hypothesis is an extension of Hypothesis 3 and posited that the technical and legitimacy-based benefits of adopting institutions with which firms are strategically aligned are more than merely additive and entirely unconnected benefits. That is, for some firms, the two distinct sources of performance enhancing benefits will reinforce one another. Formal tests can be seen by observing the significance of the interaction terms reported in Table 8. The combined social media model produced an interaction term in the predicted direction $(\mathrm{p}<.05)$ as did the Facebook model $(\mathrm{p}<.01)$. In the Twitter $(\mathrm{p}>.1)$ and YouTube $(\mathrm{p}>.1)$ models, the interactions were not significant. Thus for Facebook adopters, and for social media adopters in general, strategically aligned late adopters achieve performance improvements to a degree greater than that which is implied by simply summing the two main effects.

Hypothesis 5 suggested that for those firms that can expect neither technical nor legitimacy benefits, the costs incurred by adoption of social media will result in a decline 
in financial performance. This was tested using the ANCOVA analogs to the lagged regression models by comparing the covariate adjusted cell means of quadrant I to zero. None of the four post hoc contrasts yielded a significant result.

\section{ROBUSTNESS CHECKS}

Several robustness checks were conducted to increase confidence in obtained results and to test alternative operationalizations of key variables. Models were run using simple annual ROAs (still logged) from the year of adoption and the year following adoption with no material differences in the pattern of results. Models were also run using a longer lag such that quarters 5 to 8 after adoption were used in calculating the change in ROA instead of quarters 1 to 4 after adoption. These models suffered from a severe lack of significance with much lower R-squared metrics for the overall models suggesting that the increased lag was less suitable than the one used. Models were also run with 3 categories of strategic alignment, low, medium and high to examine the possibility that the low and high differentiators were not strategically unaligned in all of the same ways, as theorized. These models suffered from a substantial loss of significance, although the key results regarding strategic alignment largely remained significant. Additionally, models were run with strategic alignment as a continuous variable in the models where strategic alignment is not by necessity dichotomous. In light of high-end differentiators being theorized as strategically unaligned, models were also run with a squared and then a cubed term in an effort to detect a non-linear 
relationship between strategic alignment and change in performance. These models were not as predictive and seemed to fail to capture the complexity of the strategic alignment categorization as effectively as the dichotomous operationalization in the main models.

Hypotheses 1, 2, 3, and 5 were also retested using alternate methodologies. The two main effects (Hypotheses 1 and 2) were retested by using partial sample fixed-effects time series models with robust standard errors as a way to ascertain the impact of the adoption event to the portion of firms within the scope of each main effect, strategically aligned firms for Hypothesis 1 and late adopting firms for Hypothesis 2. Similarly, Hypothesis 5 was retested using fixed-effects models that included only early adopters that were not strategically aligned. All of the fixed-effects time series models $(\mathrm{H} 1, \mathrm{H} 2$, and H5) relied on an additional dummy variable called adopted to indicate whether or not adoption has occurred at each point in time and were assigned a value of 1 if the firm had adopted during or prior to that quarter and 0 otherwise. These models included quarterly data points, and included the four quarters prior to and the eight quarters following adoption to avoid having time periods too distant from the focal event. These models also used just the relative $R O A$ for each time period instead of the change in relative ROA. As an additional robustness check, fixed-effects models were also run using just the four quarters before and the four quarters after the adoption event. The latter models were less predictive, but followed the same pattern of results as the models that used the four quarters before and eight quarters after adoption.

Hypothesis 3 was retested using partial-sample lagged regression models. To retest Hypothesis 3a, the regression models included only strategically aligned firms and 
tested for a significant positive effect of being a late adopter. To retest Hypothesis $3 \mathrm{~b}$, the regression models included only late adopting firms and tested for a significant positive effect of being strategically aligned.

The retest of Hypothesis 1, using fixed-effects time series models, included all strategically aligned firms and tested whether adoption was predictive of an increase in relative ROA. Table 9 presents the results of these models. Interestingly, the results from this approach produced an adoption coefficient significantly predictive of performance only in the Twitter $(\mathrm{p}<.05)$ and YouTube models $(\mathrm{p}<.01)$. In fact, contrary to hypothesis 1 , adoption was marginally predictive of a decrease in performance among strategically aligned Facebook adopters $(\mathrm{p}<.1)$. This lack of significance for the adoption coefficient in two of the four models, including the combined model, suggests that simply adopting a new practice that is strategically aligned with firm strategy may not be sufficient to achieve technical gains. Overall, across the primary and these secondary results, Hypothesis 1 received strong support. However, the link between adoption and the achievement of technical gains may be limited by factors beyond mere adoption. 
TABLE 9

Impact to Relative ROA for Strategically Aligned Firms, Fixed-effects Time Series

\begin{tabular}{|c|c|c|c|c|c|c|c|}
\hline \multirow[b]{2}{*}{ adopted } & \multicolumn{2}{|c|}{ Combined } & Facebook & \multicolumn{2}{|c|}{ Twitter } & \multicolumn{2}{|c|}{ YouTube } \\
\hline & -0.010 & $(0.009)$ & $-0.016+\quad(0.011)$ & $0.020 *$ & $(0.011)$ & $0.024 * *$ & $(0.009)$ \\
\hline company size & $0.116 *$ & $(0.056)$ & $0.089+\quad(0.049)$ & 0.058 & $(0.051)$ & $0.102 \dagger$ & $(0.057)$ \\
\hline accounts & $-0.048 *$ & $(0.022)$ & $-0.051 * *(0.016)$ & -0.019 & $(0.013)$ & $-0.061 *$ & $(0.025)$ \\
\hline active users & $0.000 *$ & $(0.000)$ & $0.000 * * \quad(0.000)$ & 0.000 & $(0.000)$ & 0.000 & $(0.000)$ \\
\hline activity rate & $0.012 *$ & $(0.006)$ & $0.022 * \quad(0.007)$ & $0.010 *$ & $(0.005)$ & $0.022 * *$ & $(0.008)$ \\
\hline types & 0.005 & $(0.008)$ & & & & & \\
\hline constant & $-0.317 *$ & $(0.151)$ & $-0.258+\quad(0.134)$ & -0.179 & $(0.138)$ & -0.288 & $(0.155)$ \\
\hline $\mathrm{n}$ & 799 & & 764 & 710 & & 670 & \\
\hline Groups & 65 & & 62 & 61 & & 56 & \\
\hline $\mathrm{F}$ & $3.15 * *$ & & $3.98 * *$ & $2.46 *$ & & $2.24 \dagger$ & \\
\hline
\end{tabular}

The Hypothesis 2 retest used models that included only late adopters and tested whether adoption predicted an increase in performance. Results are displayed in Table 10. As with the initial test, two of the four models supported Hypothesis 2. However, it was the Facebook $(\mathrm{p}<.05)$ and Twitter models $(\mathrm{p}<.01)$ that had significant coefficients for the adoption variable.

TABLE 10

Impact to Relative ROA for Late Adopting Firms, Fixed-effects Time Series

\begin{tabular}{|c|c|c|c|c|c|c|}
\hline \multirow[b]{2}{*}{ adopted } & \multicolumn{2}{|c|}{ Combined } & Facebook & Twitter & \multicolumn{2}{|c|}{ YouTube } \\
\hline & 0.026 & $(0.033)$ & $0.068 \dagger(0.045)$ & $0.024 * *(0.009)$ & 0.009 & $(0.013)$ \\
\hline company size & 0.077 & $(0.060)$ & $0.167 \quad(0.082)$ & $(0.066)$ & 0.041 & $(0.043)$ \\
\hline accounts & -0.069 & $(0.042)$ & $-0.065 \quad(0.051)$ & $0.032 \quad(0.025)$ & -0.004 & $(0.021)$ \\
\hline active users & 0.000 & $(0.000)$ & $0.000 \quad(0.000)$ & $0.000 * *(0.000)$ & 0.000 & $(0.000)$ \\
\hline activity rate & 0.020 & $(0.015)$ & $0.018 \quad(0.016)$ & $(0.004)$ & 0.002 & $(0.007)$ \\
\hline types & -0.001 & $(0.016)$ & & & & \\
\hline constant & -0.216 & $(0.147)$ & $-0.441 \quad(0.200)$ & $(0.168)$ & -0.101 & $(0.102)$ \\
\hline $\mathrm{n}$ & 716 & & 580 & 620 & 468 & \\
\hline Groups & 61 & & 50 & 56 & 43 & \\
\hline $\mathrm{F}$ & 1.02 & & 1.27 & $2.44 *$ & 0.55 & \\
\hline \multicolumn{7}{|c|}{ Standard errors are reported in parentheses } \\
\hline \multicolumn{7}{|c|}{$\begin{array}{l}\text { Significance tests are one-tailed for directional hy potheses and two-tailed for control variables } \\
\dagger p \leq .10\end{array}$} \\
\hline
\end{tabular}


Partial-sample lagged regression models were also used to retest Hypothesis 3a by restricting the model to strategically aligned firms, then including and testing for the significance of a dummy variable for adoption timing. Results from the lagged regression models restricted to just strategically aligned firms for the combined, Facebook, Twitter, and YouTube models are reported in Table 11. In support of Hypothesis 3a, the adoption coefficient was marginally predictive in the combined model $(\mathrm{p}<.1)$ and significantly predictive in the Twitter model $(\mathrm{p}<.05)$ suggesting that among strategically aligned adopters, late adopters achieved a greater performance improvement than early adopters.

TABLE 11

Impact to Change in Relative ROA for Strategically Aligned Firms, Lagged Regression

\begin{tabular}{|c|c|c|c|c|c|c|c|}
\hline \multirow[b]{2}{*}{ adoption timing } & \multicolumn{2}{|c|}{ Combined } & \multicolumn{2}{|c|}{ Facebook } & Twitter & \multicolumn{2}{|c|}{ YouTube } \\
\hline & $0.093 \dagger$ & $(0.066)$ & 0.020 & $(0.076)$ & $0.126 *(0.059)$ & -0.046 & $(0.104)$ \\
\hline company size & 0.003 & $(0.034)$ & $-0.073 \dagger$ & $(0.043)$ & $-0.060 \dagger \quad(0.035)$ & 0.008 & $(0.042)$ \\
\hline activity rate & 0.005 & $(0.050)$ & $0.155 *$ & $(0.061)$ & $0.077 \dagger \quad(0.041)$ & $0.159 *$ & $(0.070)$ \\
\hline active users & 0.000 & $(0.000)$ & 0.000 & $(0.000)$ & $-0.002 * *(0.001)$ & 0.000 & $(0.000)$ \\
\hline accounts & -0.113 & $(0.134)$ & -0.086 & $(0.116)$ & $(0.076)$ & -0.185 & $(0.186)$ \\
\hline types & 0.030 & $(0.050)$ & & & & & \\
\hline constant & -0.053 & $(0.103)$ & -0.028 & $(0.135)$ & $0.231 * *(0.082)$ & 0.079 & $(0.165)$ \\
\hline $\mathrm{n}$ & 65 & & 62 & & 61 & 56 & \\
\hline Adjusted R ${ }^{2}$ & 0.07 & & 0.14 & & 0.16 & 0.03 & \\
\hline$\Delta$ Adj. $\mathrm{R}^{2}$ & 0.02 & & -0.01 & & 0.05 & -0.02 & \\
\hline $\mathrm{F}$ & 1.86 & & $2.91 *$ & & $3.22 *$ & 1.32 & \\
\hline
\end{tabular}

Standard errors are reported in parentheses

Significance tests are one-tailed for directional hypotheses and two-tailed for control variables

Change in Adj. $\mathrm{R}^{2}$ is the change from model excluding the adoption timing variable (sm_late, etc.)

$\dagger \mathrm{p} \leq .10$

$* \mathrm{p} \leq .05$

$* * \mathrm{p} \leq .01$

Hypothesis $3 \mathrm{~b}$ was also retested using partial-sample lagged regression models by restricting the models to late adopting firms and then including and testing for the significance of a strategic alignment dummy variable (see Table 12). Using this approach, all four models $(\mathrm{p}<.01, \mathrm{p}<.01, \mathrm{p}<.01$, and $\mathrm{p}<.05)$ supported Hypothesis $3 b$. 
TABLE 12

Impact to Change in Relative ROA for Late Adopting Firms, Lagged Regression

\begin{tabular}{|c|c|c|c|c|c|}
\hline & Combined & Facebook & Twitter & You' & ube \\
\hline strategic alignment & $0.122 * *(0.049)$ & $0.147 * *(0.057)$ & $0.083 * *(0.034)$ & $0.075 *$ & $(0.042)$ \\
\hline company size & $0.056 \quad(0.034)$ & $(0.037)$ & $(0.025)$ & $0.080 *$ & $(0.037)$ \\
\hline activity rate & $0.040 \quad(0.059)$ & $(0.080)$ & $(0.030)$ & 0.077 & $(0.050)$ \\
\hline active users & $(0.000)$ & $(0.000)$ & $-0.001 * \quad(0.000)$ & 0.000 & $(0.000)$ \\
\hline accounts & $-0.178 \quad(0.139)$ & -0.183 & $(0.079)$ & -0.148 & $(0.206)$ \\
\hline types & $0.082 \dagger(0.049)$ & & & & \\
\hline constant & $-0.259 * \quad(0.102)$ & -0.170 & $(0.081)$ & -0.292 & $(0.174)$ \\
\hline $\mathrm{n}$ & 61 & 50 & 56 & 43 & \\
\hline Adjusted $\mathrm{R}^{2}$ & 0.23 & 0.10 & 0.12 & 0.10 & \\
\hline$\Delta$ Adj. $\mathrm{R}^{2}$ & 0.08 & 0.12 & 0.07 & 0.05 & \\
\hline $\mathrm{F}$ & $2.69 *$ & $2.05 \dagger$ & $2.57 *$ & 1.98 & \\
\hline \multicolumn{6}{|c|}{ Standard errors are reported in parentheses } \\
\hline \multicolumn{6}{|c|}{ Significance tests are one-tailed for directional hypotheses and two-tailed for control variables } \\
\hline \multicolumn{6}{|c|}{$\begin{array}{l}\text { Change in Adj. } \mathrm{R}^{2} \text { is the change from model excluding the adoption timing variable (sm_late, etc.) } \\
\mathrm{p}<10\end{array}$} \\
\hline \multicolumn{3}{|l|}{$* \mathrm{p} \leq .05$} & & & \\
\hline
\end{tabular}

The Hypothesis 5 retest using fixed-effects time series models, included only strategically unaligned early adopters. Results (see Table 13) using this method were more conclusive in supporting Hypothesis 5 with the combined $(\mathrm{p}<.05)$ and YouTube $(\mathrm{p}$ $<.05)$ showing a significant relationship between adoption and a decline in performance and the Twitter model $(\mathrm{p}<.1)$ showing a marginally significant relationship.

TABLE 13

Impact to Relative ROA for Strategically Unaligned Early Adopters, Fixed-effects Time Series

\begin{tabular}{|c|c|c|c|c|c|c|c|c|}
\hline \multirow[b]{2}{*}{ adopted } & \multicolumn{2}{|c|}{ Combined } & \multicolumn{2}{|c|}{ Facebook } & \multicolumn{2}{|c|}{ Twitter } & \multicolumn{2}{|c|}{ YouTube } \\
\hline & $-0.009 *$ & $(0.005)$ & 0.000 & $(0.004)$ & $-0.008 \dagger$ & $(0.005)$ & $-0.015 *$ & $(0.008)$ \\
\hline company size & -0.039 & $(0.059)$ & 0.017 & $(0.045)$ & 0.075 & $(0.050)$ & -0.027 & $(0.072)$ \\
\hline accounts & 0.014 & $(0.012)$ & 0.008 & $(0.010)$ & -0.008 & $(0.011)$ & 0.007 & $(0.013)$ \\
\hline active users & 0.000 & $(0.000)$ & 0.000 & $(0.000)$ & 0.000 & $(0.000)$ & 0.000 & $(0.000)$ \\
\hline activity rate & -0.001 & $(0.005)$ & -0.005 & $(0.004)$ & 0.008 & $(0.006)$ & 0.003 & $(0.005)$ \\
\hline types & -0.002 & $(0.005)$ & & & & & & \\
\hline constant & 0.135 & $(0.187)$ & -0.047 & $(0.137)$ & -0.222 & $(0.153)$ & 0.096 & $(0.240)$ \\
\hline $\mathrm{n}$ & 311 & & 357 & & 297 & & 298 & \\
\hline Groups & 25 & & 29 & & 24 & & 24 & \\
\hline $\mathrm{F}$ & 1.24 & & 1.05 & & 1.25 & & 1.10 & \\
\hline \multicolumn{9}{|c|}{ Standard errors are reported in parentheses } \\
\hline $\begin{array}{l}\text { Significance tests } \\
\dagger \mathrm{p} \leq .10 \\
* \mathrm{p} \leq .05 \\
* * \mathrm{p} \leq .01\end{array}$ & e-tailed for & rectional h & d two-tail & or control & & & & \\
\hline
\end{tabular}


Overall, the alternate methods used to retest my hypotheses are similar to the results of the initial tests. The main exception is the support for Hypothesis 5 which is supportive of the hypothesis using the alternate methods and inconclusive in the initial tests.

\section{DISCUSSION}

Until recently, there has been very little debate regarding whether firms that adopt new practices do so out of motivations to pursue both social and economic benefits. In fact, the two-stage model of diffusion (Tolbert \& Zucker, 1983), the longstanding paradigm for explaining the motives of isomorphic adopters, firmly contends that early adopters seek the technical or economic efficiency benefits of a new practice and late adopters seek only legitimacy, or the benefits that flow from social approval. However, the two-stage model and its basic assumptions are increasingly being called into question (Love \& Cebon, 2008; Lounsbury, 2007). In particular, recent work has provided strong evidence that adoption timing is not a clear indicator of adoption motivation (Kennedy \& Fiss, 2009). Similarly, I also break from the assumptions of the two-stage model and assume that managers are interested in both the technical and social benefits of new practices regardless of adoption timing. I move this area of institutional thought forward in two major ways by directly addressing whether firms that might possess these dual motives, social legitimacy and technical or economic efficiency, can reasonably pursue the achievement of both. First, received theory suggests that the upside benefits from 
both sources tend not to be available to firms simultaneously (Tolbert \& Zucker, 1983; Westphal, Gulati, \& Shortell, 1997) because firms capable of achieving technical gains will have adopted the practice early on. In response, I develop explanations for why some firms that are capable of achieving technical gains will be late adopters. Thus I contribute to the diffusion of institutions literature by updating past theorizing that suggests that such firms are early adopters. Second, the existence of firms that are capable of achieving technical and legitimacy gains strongly supports the contention that firms are motivated to pursue both (Kennedy \& Fiss, 2009), but the current study is the first to empirically confirm the existence of these firms and their ability to achieve both types of adoption benefits. Thus, my first two contributions are the expansion of institutional theory's explanations of adoption motivations by arguing for the concurrent availability of both legitimacy and technical benefits to some late adopters and empirical corroboration for this expanded model. These two major contributions then opened the door to a third significant contribution to the institutional theory literature. This study is the first to observe the interplay of legitimacy gains and technical gains. I argued and found that technical and legitimacy benefits interact and enhance one another in their impact to the financial performance of adopting firms. Finally, this study represents one of the only studies of social media within the organizations and management literatures. Because of its incredible growth and extreme pervasiveness in society and the workplace, social media is fast becoming a topic and a context that will impact organizations.

To test my assertions, I analyzed the diffusion of social media in several industries in which some firms rely heavily on brand awareness while other firms in those 
same industries do not. The key reconceptualization I provide is the use of strategic alignment as the key distinguisher of which firms can expect to achieve technical gains through adoption of new practices, instead of the use of adoption timing wherein early adopters seek them and later adopters do not. This provides a clear advantage over the previous model that relied on adoption timing to proxy for both types of adoption benefits: technical gains for early adopters and legitimacy gains for late adopters. The previous approach implicitly assumes that all early adopters are strategically aligned with the practice while all late adopters are not. Instead, I categorize firms so that strategically aligned firms obtain technical gains and late adopting firms obtain legitimacy. While the two-stage model only allows for the existence of firms in quadrants II and IV of Figure 1, my expanded model allows for strategic alignment and adoption timing to fully cross, resulting in 4 categories of firms with 4 distinct profiles of which adoption benefits are available at the time of adoption. Consequently, these two theoretically distinct logics can be empirically separated and viewed in a way that allows us to see when they are each achievable and how they might interact.

As predicted, I found that strategic alignment, those firms with moderate to high levels of differentiation, is positively linked to improved financial performance upon adoption of social media. This relationship was detected when both early and late adopters were considered jointly (H1) as well as when considering just late adopters $(\mathrm{H} 3 b)$. This finding is unique in institutional theory studies in empirically corroborating the recent contention that late adopters are motivated by the prospect of achieving the technical benefits of adoption (Kennedy \& Fiss, 2009) rather than sole interest in and 
ability to achieve legitimacy benefits. Not only do firms possess motives for social and economic gains, the current study provides evidence that they can actually achieve them. This also contradicts the two-stage model of diffusion (Tolbert \& Zucker, 1983) and subsequent related work that focuses on technical and legitimacy motives and gains as a naturally occurring trade off with temporal bounds on each (Barreto \& Baden-Fuller, 2006; Westphal, Gulati, \& Shortell, 1997). It seems that the pursuit and achievement of technical gains is independent of timing within the diffusion process. If adoption of an emerging practice is compelling to organizations for reasons of technical efficiency, it is not reasonable to expect the effect of adoption by such firms to change across the timing of the diffusion process.

The finding that a moderate to high level of differentiation is positively related to financial performance for early and late adopters provides strong evidence that strategic alignment is linked to technical gains, which also addresses a recent call to look beyond adoption timing as a proxy for adoption motivation (Kennedy \& Fiss, 2009). While the current study does not measure firm motivation, it does capture that firms have reason to be motivated by technical gains across the entire temporal breadth of the diffusion process. Because strategic alignment predicts technical benefits across early and late adoption time periods, it is suggested that future work on institutional isomorphism consider strategic alignment as a more appropriate indicator of motivation to achieve technical or economic efficiency than adoption timing.

My finding that late adoption is positively associated with improved financial performance sides with recent meta-analytic results (Heugens \& Lander, 2009) in 
contradicting a longstanding foundational tenet of institutional theory that positions isomorphic conformity as in sharp conflict with efficiency (DiMaggio \& Powell, 1983; Meyer \& Rowan, 1977). This is likely due to certain benefits of legitimacy impacting firms economically since many late adopters are not strategically aligned and are not likely to benefit from technical gains through adoption. The link between legitimacy and improved financial performance might be attributable to mechanisms such as aiding an organization in becoming a more attractive business partner and thus more likely to attract resources at favorable terms (Greenwood et al., 2008) or in helping a firm avoid reputational damage (Deephouse, 1999). In the current study, this positive relationship was not found across all types of social media (e.g. YouTube), but results more strongly supported that of the meta-analysis: that overall there is a positive relationship. This is a critical finding for the expanded view that both types of motivations and gains exist across the diffusion process since I infer the existence of legitimacy gains through an economic or "substantive" performance measure rather than a social or "symbolic" one. In fact, this constitutes an additional point of departure from the majority perspective (beyond timing) that technical and legitimacy gains are mutually exclusive because the majority perspective also assumes isomorphic conformers (late adopters) not only achieve just legitimacy gains, but that those gains are only social or symbolic in nature (Scott, 2001; Meyer \& Rowan, 1977) and not economic. The finding that late adoption of an institution is related to improved financial performance supports the recent metaanalysis. However, and more importantly, because conformity to institutions also strongly relates to social or symbolic performance (Deephouse \& Suchman, 2008), observing the interaction term for strategic alignment and adoption timing also allows for 
a closer inspection of how social and economic logics might interact and influence one another.

Hypotheses 3 and 4 built upon one another to predict that technical and legitimacy gains are not mutually exclusive and that they even positively interact such that strategically aligned late adopters improve performance by an amount beyond the effects of technical and legitimacy gains in isolation. Results were clear that firms capable of achieving both types of gains saw greater performance improvements than firms capable of achieving only one (technical or legitimacy). This provides strong evidence towards dispelling the myth that social and economic goals necessarily conflict. It seems that because there is often a range of acceptable responses to institutional pressures (Dacin, Goodstein, \& Scott, 2002) there is often ample opportunity to pursue isomorphic conformance within the bounds of strategic expedience. But, do legitimacy and technical gains enhance one another? Do firms that excel in achieving technical proficiency with a new practice receive more social benefits than firms that adopt symbolically? Or does social approval enhance a firm's ability to excel technically? Past conceptualizations of the two disparate logics have precluded any meaningful way for these questions to be asked or answered since they were not considered to be coincident to each other. In light of recent findings, along with the current findings, these have become the next logical questions to answer in order to better understand how institutional behaviors and economically rational behaviors might coexist and even impact one another. The adoption of social media in general, and Facebook specifically produced very interesting results regarding the interaction of legitimacy (late adopters) and technical gains 
(strategically aligned). In these models, the market relative ROA was seen to increase for these firms to a degree beyond what can be explained by the effects of technical and legitimacy gains in isolation. One explanation for how this might occur is that technical leaders receive greater social gains than others (Rindova, Pollock \& Hayward, 2006). Essentially, firms get a reputation bonus in the eyes of external constituents such as consumers or resource providers for being an expert or highly successful technically. The enhanced reputation would then manifest itself in ways that impact financial performance, such as higher consumer demand or more favorable terms with suppliers or banks. If such a dynamic exists, managers are right to jointly consider the social and economic implications of adopting institutions. They may, in fact, be intertwined so closely that, as a manager, it is senseless to consider them as entirely separate matters. One promising avenue for future research is to examine whether managers indeed consider social and economic logics in relation to one another when making adoption decisions or whether they consider them both, but as isolated and unrelated factors. In addition, future research might also seek to better understand the nature of the positive interaction between technical and legitimacy gains, whether reputation enhancement is in fact one mechanism through which this occurs, and what other mechanisms might also drive this effect.

One key insight into the dynamic of social and economic gains enhancing one another is that adoption without substantial implementation would prevent the expression of this potential positive interaction from occurring. As noted in prior work, low-effort symbolic adoption of institutions can decouple the social and economic mechanisms 
(Westphal \& Zajac, 1994), which in this context would lead to the achievement of positive legitimacy gains but without the achievement of positive technical gains. Because past theorizing has focused on decoupling as a method for avoiding the economic downside of adopting institutions that necessarily conflict with efficiency, managers adhering to the decoupling mindset might inadvertently be adopting what could be technically beneficial practices in such a way that they forego easily achievable gains. While sometimes characterized by institutional theories as such, managers are typically not 'sociological dopes' (Heugens \& Lander, 2009) that casually make decisions to adopt new practices without considering the ramifications. Nevertheless, future research should seek to extend the decoupling literature and investigate the degree to which this mindset exists among managers and with what consequences.

While implementation effort was carefully controlled for in the analysis by including three measures of effort, the timing of adoption was operationalized with only minor attention paid to implementation effort. Firms were determined to have adopted once they had cleared a fairly low implementation hurdle so as to, appropriately, include all adopting firms in the adoption category regardless of whether they were symbolic or substantive adopters. Consequently, the adoption timing dichotomy is made based on symbolic adoption as the minimum requirement. Because symbolic adoption is correlated with implementation effort, it can still be predictive of technical gains by strategically aligned adopters, but might understate the strength of the relationship and its interaction with legitimacy. One possible reconceptualization of the dichotomy (and interaction) of social and economic logics and their accompanying benefits is to consider 
both symbolic and substantive adoption as types of adoption, one predictive of legitimacy gains and one predictive of technical gains. In other words, merely having signed up for social media accounts is enough to symbolically adopt and therefore achieve conformance and its attendant legitimacy, while actively using social media is the only way to reap the technical benefits of the practice. To test this reconceptualization I retained adopted as the measure of symbolic adoption and implemented activity rate as a measure of implementation effort. Because this alternative view does not change the way in which firms are categorized as early or late adopters nor does it change whether they are categorized as strategically aligned or unaligned, not all hypotheses can be tested in precisely the same way as done in the initial analysis. At a minimum, I was able to test the underlying premise of each one.

Hypothesis 1 can be reevaluated by replacing adopted with activity rate as the key independent variable in the fixed-effects time series models that were used as a robustness check for Hypothesis 1 (included just strategically aligned firms). Results of doing so can be seen in Table 9. In all four models (SM: $\mathrm{p}<.05$, FB: $\mathrm{p}<.01$, TW: $\mathrm{p}<$ $.05)$, YT: $\mathrm{p}<.01)$ activity rate was a significant predictor of improvement in relative ROA. This confirmed that implementation effort is positively related to the achievement of technical gains. No changes to the fixed-effects time series models that included just late adopters are required to test Hypothesis 2 under the reconceptualization since the key independent variable remains the same in this case. Although, it is interesting to note that none of the four models in Table 10 found activity rate to be predictive of changes in 
financial performance. In contrast to technical gains, it seems that legitimacy gains are not contingent upon, and therefore not significantly predicted by implementation effort.

To aid in reevaluating Hypotheses 3 and 5, fixed-effects time series models were used to test the influence of formal adoption and activity rate on each quadrant. Summarized results are displayed in Table 14. Retesting Hypothesis 3 in a way directly analogous to the initial tests is not feasible using both activity rate and formal adoption. However, it does allow for the testing of whether formal adoption and activity rate are both independently predictive of change in performance in quadrant III as opposed to just activity rate in quadrant II and just formal adoption in quadrant IV. As expected, and consistent with the Hypothesis 1 reevaluation, implementation effort positively impacted performance in quadrant II in three of the four models and in quadrant III in three of the four models. However, formal adoption predicted improved performance only in quadrant IV (3 of 4) but not in quadrant IV. This could be due to a number of things, two of which I will mention. First, the small sample size may have precluded a replication of the legitimacy main effect within each of the two smaller samples. Second, it is also possible that the "main effect" is merely a manifestation of the significant interaction. In the case of the latter, this could be interpreted to suggest that legitimacy does not provide a financial impact to firms that are not strategically aligned with the adopted practice but does for those that are strategically aligned. This offers one explanation for the contradictory results of past research regarding the question of whether isomorphic adoption is positively related to financial performance and not merely symbolic performance. If the relationship between institutional legitimacy and 
financial gain is moderated by another variable it is expected that inconsistent results would surface among studies that do not account for the moderating variable.

It is also noteworthy that both formal adoption and activity rate were positively related to improved performance ( 3 of 4 models) in quadrant III. This supports the predictions of Hypotheses 3 and 4 that predicted that strategically aligned late adopters will realize performance gains through more than a single mechanism. It seems that adoption mechanisms indicative of both institutional processes and economic rationality can work simultaneously to positively influence financial performance. This is in sharp contrast to prior institutional diffusion models such as the two-stage model that allow for just one mechanism to operate at any given time.

TABLE 14

Impact of Formal Adoption and Implementation Effort on Change in Relative ROA

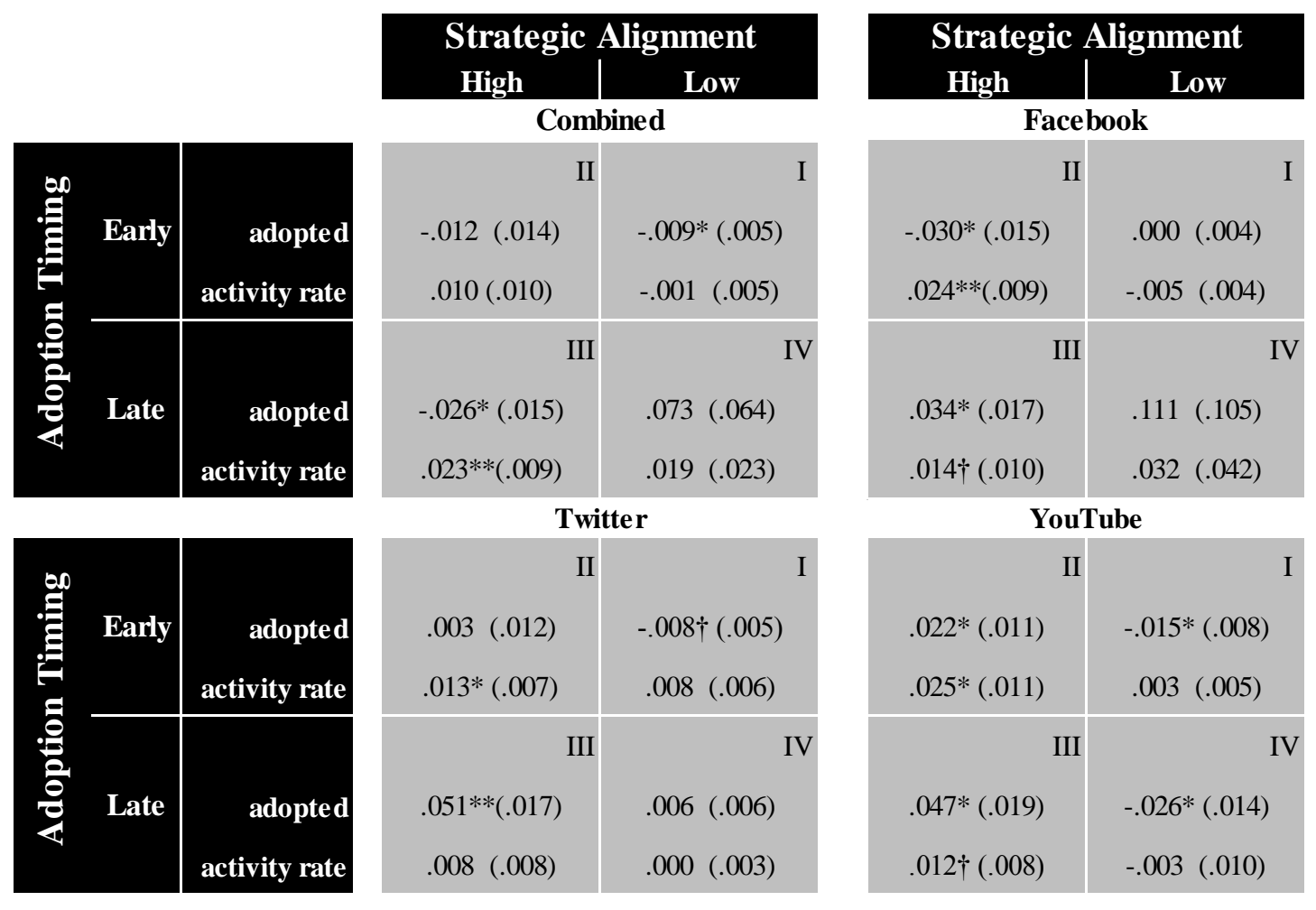


Reevaluating Hypothesis 5 also revealed some interesting insights. The initial argument in support of this hypothesis was that adoption would negatively influence strategically unaligned early adopters because they would not receive legitimacy or technical gains but would expend valuable resources to adopt. This logic suggests activity rate would be the culprit for the negative impact of adoption on firm performance as opposed to formal adoption since the mere creation of social media accounts requires almost no resources but posting content to accounts, monitoring activity, and interacting with other social media users requires a substantial ongoing resource commitment. Contrary to this argument, it was formal adoption that was significantly predictive of poorer performance among firms in quadrant I ( 3 of 4 models) while activity rate was not related to changes in performance at all. One explanation for this result is that there is a cost of adopting illegitimate practices (Sanders \& Tuschke, 2007). This explanation is also consistent with the findings that there seems to be an overall late adoption (legitimacy) main effect, but the main effect does not independently manifest itself in strategically aligned late adopters. This pattern of results is to be expected if the adoption of a particular institution has the effect, not of providing positive benefits, but of preventing the negative consequences of being perceived as illegitimate (Abrahamson, 1991; (Chen, 2011; De Choudhury, 2011; Doran, 2013; Eller, 2012; George, Chattopadhyay, Sitkin, \& Barden, 2006). In other words, early adoption leads to legitimacy loss and late adoption leads to legitimacy maintenance. Under this scenario, late adoption is a loss avoidance strategy where failure to adopt leads to a loss of legitimacy. One weakness inherent to the empirical model of the current study is the inclusion of only firms that have adopted the institution. Unfortunately, this lack 
prevents the comparison of adopters and non-adopters to see if the positive relationship between adoption and legitimacy gains exists in the late time period. Furthermore, because the vast majority of firms in the current study's context have adopted social media, future research that might explore this question must utilize a different context where there is a substantial number of firms that have not adopted the institutionalized practice to see if those that choose not to adopt the institution suffer a decrease in legitimacy.

There were some interesting differences among the combined social media, Facebook only, Twitter only, and YouTube only models, one in particular that especially merits discussion. YouTube stood out as unique due to a negative overall relationship between late adoption and financial improvement. In the case of YouTube, firms that adopted early in the diffusion process saw greater performance improvements than those that adopted late, or alternatively, they saw smaller decreases in performance as late adopters. This might be expected if YouTube had not become an institution to the degree that social media generally has; rather it had become the opposite, or expected and taken for granted that firms should not adopt YouTube. In fact, the data suggest an interesting double standard in the case of YouTube. Financial performance of strategically unaligned firms is negatively impacted by formal adoption (early and late), yet it is positively impacted for strategically aligned firms (early and late). Thus, it appears that the institutionalization of YouTube might be dependent on firm strategy such that strategically aligned firms are expected to adopt and unaligned firms are expected not to adopt. If this is the case, unaligned late adopters would experience greater sanctions for 
adopting than unaligned early adopters as the practice increases in illegitimacy over time. The pattern of results for YouTube is very consistent with this interpretation. In summary, both strategic alignment and adoption timing matter, but early adoption is better, and there is no interaction between timing and strategic alignment since there would be no technical boon driven by an enhanced reputation from simply avoiding a practice that is looked down upon. In practical terms, results from this study suggest that YouTube might be a risky form of social media for strategically unaligned firms in sample industries, especially as a late adopter. Theoretically, the implications of this potential explanation are intriguing because the pattern of YouTube results might represent a unique occurrence of social and economic logics interacting, not in how they impact firm outcomes, but in the shaping of the institutional environment itself. This is an interesting avenue for future research that would be valuable to the ongoing discussion about the interplay of social and economic motivations and outcomes (e.g. Schneiberg \& Soule, 2005; Lounsbury, 2007).

One final opportunity for future research relates to the context of this study. Social media is an entirely new area in organizational and strategy research and is also an area that is evolving quickly. An example of this can be seen among firms that were rated very highly as differentiators and were categorized as strategically unaligned with the social media due to the incompatibility of social media with the typical consumer of luxury goods and with their preferred purchasing experience. This strategic misalignment may actually be shifting in the last couple of years as recent trends indicate that high fashion and other luxury goods are gaining greater customer acceptance for 
having an online storefront and a social media presence (Morphy, 2012). Also contributing to this shift, the speed with which consumers make luxury purchases has increased dramatically with over one third stating a preference to buy the same day they decide they are interested (Doran, 2013). Highly differentiated firm were appropriately categorized as strategically unaligned with social media practices for the time frame of the current study, but that may be in the process of changing. With these recent and ongoing changes, the combination of social media and luxury goods represents a valuable opportunity to observe and gain understanding about shifting institutional environments.

\section{CONCLUSION}

In this study I sought to examine the role of social and economic logics and the consequences of isomorphic adoption. In particular, I have argued that firms that adopt new practices do not necessarily have to choose between technical, or economic efficiency benefits, and legitimacy benefits. Firms that adopt in order to look good are not precluded from also doing it well. And conversely, firms that adopt useful practices are not impeded from reaping any social benefits that may be available. In fact, for some firms, technical gains and legitimacy gains are not only compatible, they also reinforce one another in improving firm performance. Whereas past research has often implied social motivations and economic motivations of firms from adoption timing, I suggest that adoption timing is a reasonable proxy for social motivations but strategic alignment operates independently of adoption timing and serves as a more appropriate indicator of 
potential for the technical benefits of adoption. Thus I contribute to the literature on the diffusion of institutional practices first, by expanding, and second, by testing the explanations of adoption motivations. I also contribute by providing the first study to examine the interplay of the technical and legitimacy benefits of adopting an institutionalized practice. A fourth contribution to the institutional theory literature is the innovative use of strategic alignment along with adoption timing as a better combination of proxies for adoption motivations than just adoption motivation. Finally, as one of the only studies to utilize social media within the organizations and management literatures, I introduce a unique and increasingly important empirical context to the literatures. 


\section{REFERENCES}

60SecondMarketer. 2011. Are there really more mobile phones that toothbrushes?, Retrieved April 9, 2012, from http://60secondmarketer.com/blog/2011/10/18/more-mobile-phones-thantoothbrushes.

Abrahamson, E. 1991. Managerial fads and fashions: The diffusion and rejection of innovations. The Academy of Management Review, 16: 586-612.

Abrahamson, E., \& Rosenkopf, L. 1993. Institutional and competitive bandwagons: Using mathematical modeling as a tool to explore innovation diffusion. The Academy of Management Review, 18: 487-517.

Arrington, M. 2008. Obama sets record with january donations; online donations $88 \%$ of total. TechCrunch. Retrieved April 9, 2012, from

http://techcrunch.com/2008/02/04/obama-sets-record-with-january-donationsonline-donations-88-of-total/

Bajarin, T. 2012. 6 reasons Apple is so successful, Time. Retrieved May, 8, 2012, from http://techland.time.com/2012/05/07/six-reasons-why-apple-is-successful

Barney, J. 1991. Firm resources and sustained competitive advantage. Journal of Management, 17: 99-120.

Baron, J. N., Davis-Blake, A., \& Bielby, W. T. 1986. The structure of opportunity: how promotion ladders vary within and among organizations. Administrative Science Quarterly, 31: 248-273.

Barreto, I., \& Baden-Fuller, C. 2006. To conform or to perform? Mimetic behaviour, legitimacy-based groups and performance consequences. Journal of management studies, 43: 1559-1581.

Basu, o. N., dirsmith, m. W., \& gupta, p. P. 1999. The coupling of the symbolic and the technical in an institutionalized context: The negotiated order of the gao's audit reporting process. American Sociological Review, 64: 506-526.

Battilana, J., Leca, B., \& Boxenbaum, E. 2009. How actors change institutions: Towards a theory of institutional entrepreneurship. The Academy of Management Annals, 3: 65-107.

Baum, J. A. C., \& Oliver, C. 1991. Institutional linkages and organizational mortality. Administrative Science Quarterly, 36: 187-218. 
Beer, D. D. 2008. Social network(ing) sites...revisiting the story so far: A response to Danah Boyd \& Nicole Ellison. Journal of Computer-Mediated Communication, 13: 516-529.

Bogner, W. C., \& Barr, P. S. 2000. Making Sense in Hypercompetitive Environments: A cognitive explanation for the persistence of high velocity competition.

Organization Science, 11: 212-226.

Boxenbaum, E., \& Jonsson, S. 2008. Isomorphism, diffusion and decoupling. In R. Greenwood, C. Oliver, K. Sahlin, \& R. Suddaby (Eds.), The sage handbook of organizational institutionalism: 49-77. Los Angeles: Sage.

Boyd, D. M., \& Ellison, N. B. 2007. Social network sites: Definition, history, and scholarship. Journal of Computer-Mediated Communication, 13: 210-230.

Brauer, M., \& Bourhis, R. Y. 2006. Social power. European Journal of Social Psychology, 36: 601-616.

Briggs, C. 2009. BlendTec will it blend?Viral video case study: SociaLens. Retrieved April 9, 2012, from http://www.socialens.com/wpcontent/uploads/2009/04/20090127_case_blendtec11.pdf

Brunnson, N. 1989. The Organization of Hypocrisy: Talk, Decisions and Actions in Organizations: John Wiley and Sons.

Burns, T., \& Stalker, G. M. 1961. The Management of Innovation. London: Tavistock.

Carlyon, T. 2011. Facebook marketing strategies for big box retailers. Unpublished 1505990, The College of St. Scholastica, United States -- Minnesota.

Carroll, V. P., Lee, H. L., \& Rao, A. G. 1986. Implications of salesforce productivity heterogeneity and demotivation: A navy recruiter case study. Management Science, 32: 1371-1388.

Chandler, A. D. 1962. Strategy and structure: Chapters in the history of the American industrial enterprise. Cambridge, MA: MIT Press.

Chen, K.-J. 2011. A test of the spiral of silence theory on young adults' use of social networking sites for political purposes. Unpublished M.S., Iowa State University, United States -- Iowa.

Dacin, M. T., Goodstein, J., \& Scott, W. R. 2002. institutional theory and institutional change: Introduction to the special research forum. The Academy of Management Journal, 45: 43-56.

Daft, R. L., \& Lengel, R. H. 1986. Organizational information requirements, media richness and structural design. Management Science, 32: 554-571. 
De Choudhury, M. 2011. Analyzing the dynamics of communication in online social networks. Unpublished Ph.D., Arizona State University, United States -- Arizona.

Dean Jr, J. W., \& Snell, S. A. 1996. The strategic use of integrated manufacturing: An empirical examination. Strategic Management Journal, 17: 459-480.

Dean, T. J., Brown, R. L., \& Bamford, C. E. 1998. Differences in large and small firm responses to environmental context: strategic implications from a comparative analysis of business formations. Strategic Management Journal, 19: 709-728.

Deephouse, D. L. 1996. Does isomorphism legitimate? The Academy of Management Journal, 39: 1024-1039.

Deephouse, D. L. 1999. To be different, or to be the same? It's a question (and theory) of strategic balance. Strategic Management Journal, 20: 147-166.

Deephouse, D. L., \& Suchman, M. C. 2008. Legitimacy in organizational institutionalism. In R. Greenwood, C. Oliver, K. Sahlin, \& R. Suddaby (Eds.), The sage handbook of organizational institutionalism: 49-77. Los Angeles: Sage.

Digitalbuzz. 2011. Mobile marketing. Retrieved April 9, 2012, from http://digitalbuzz.s3.amazonaws.com/wp-content/uploads/2011/04/2011-mobilestatistics.jpg

DiMaggio, P. J. 1988. Interest and agency in institutional theory. In P. S. Tolbert (Ed.), Institutional Patterns and Organizations: Culture and Environment: 3-22. Cambridge, MA: Ballinger.

DiMaggio, P. J., \& Powell, W. W. 1983. The Iron Cage Revisited: institutional isomorphism and collective rationality in organizational fields. American Sociological Review, 48: 147-160.

Donaldson, L. 1995. American Anti-management Theories of Organization. Cambridge, UK: Cambridge University Press.

Doran, S. 2013. how social media \& luxury brand websites are impacting eCommerce, Luxury Society. Retrieved March 17, 2013 from http://luxurysociety.com/articles/2013/02/how-social-media-luxury-brandwebsites-are-impacting-ecommerce

Edelman, D. 2012. Social media in the C-suite, Forbes. Retrieved April 9, 2012, from http://www.forbes.com/sites/mckinsey/2012/03/22/social-media-in-the-c-suite/

Edelman, L. B. 1990. Legal Environments and Organizational Governance: The expansion of due process in the american workplace. American Journal of Sociology, 95: 1401-1440. 
Edelman, L. B. 1992. Legal ambiguity and symbolic structures: Organizational mediation of civil rights law. American Journal of Sociology, 97: 1531-1576.

Edelman Trust Barometer. (2008). Retrieved April, 9, 2012, from http://www.edelman.com/trust/2008/trustbarometer08_final.pdf

Edelman Trust Barometer. (2010). Retrieved April, 9, 2012, from http://www.edelman.com/trust/2010/docs/2010_trust_barometer_executive_summ ary.pdf

Eller, L. S. 2012. Social media as avenue for personal learning for educators: Personal learning networks encourage application of knowledge and skills. Unpublished Ed.D., Pepperdine University, United States -- California.

eMarketer. 2011. Stats of the day. April 9, 2012, from http://mediabistro.com/alltwitter/files/2011/12/social-media-statistics.jpg

Facebook. 2012. Newsroom. Retrieved April 9, 2012, from http://newsroom.fb.com/content/default.aspx?NewsAreaId=22

Federal Election Commission. 2008. 2008 Presidential campaign finance. Retrieved April 27, 2012, from http://www.fec.gov/disclosurep/pnational.do

Fiol, C. M., \& O'Connor, E. J. 2003. Waking up! Mindfulness in the Face of Bandwagons. The Academy of Management Review, 28: 54-70.

Fischer, E., \& Reuber, A. R. 2011. Social interaction via new social media: (How) can interactions on Twitter affect effectual thinking and behavior? Journal of Business Venturing, 26: 1-18.

Friedland, R. 2002. Money, sex, and god: The erotic logic of religious nationalism. Sociological Theory, 20: 381-425.

Garrity, B. 2011. Social media join toolit for hunters of disease, The New York Times. Retrieved from http://www.nytimes.com/2011/06/14/health/research/14social.html

George, E., Chattopadhyay, P., Sitkin, S. B., \& Barden, J. 2006. Cognitive underpinnings of institutional persistence and change: A framing perspective. Academy of Management Review, 31: 347-365.

Giddens, A. 1984. The constitution of society: Outline of th theory of structuration. Cambridge, UK: Polity Press.

Goffman, E. 1959. Presentation of self in everyday life. New York: Doubleday Anchor Books. 
Goodstein, J. D. 1994. Institutional pressures and strategic responsiveness: Employer involvement in work-family issues. The Academy of Management Journal, 37: 350-382.

Greenwood, R., \& Hinnings, C. R. 2006. Radical organizational change. In S. Clegg, C. Hardy, W. W. Nord, \& T. Lawrence (Eds.), Handbook of Organizational Studies.

Greenwood, R., Oliver, C., Sahlin, K., \& Suddaby, R. 2008. Introduction. In R. Greenwood, C. Oliver, K. Sahlin, \& R. Suddaby (Eds.), The sage handbook of organizational institutionalism: 1-46. Los Angeles: Sage.

Grooters, S. 2011. Lessons in social media fundraising: Applying global tactics at a local level. Unpublished 1500861, University of Southern California, United States -- California.

Hannan, M. T., \& Freeman, J. 1977. The population ecology of organizations. American Journal of Sociology, 82: 929-964.

Hannan, M. T., \& Freeman, J. 1984. Structural inertia and organizational change. American Sociological Review, 49: 149-164.

Hasse, R., \& Krücken, G. 2008. Systems theory, societal contexts, and organizational heterogeneity. In R. Greenwood, C. Oliver, K. Sahlin, \& R. Suddaby (Eds.), The sage handbook of organizational institutionalism: 539-559. Los Angeles: Sage.

Haveman, H. A., \& David, R. J. 2008. Ecologists and institutionalists: Friends or foes? In R. Greenwood, C. Oliver, K. Sahlin, \& R. Suddaby (Eds.), The sage handbook of organizational institutionalism: 573-595. Los Angeles: Sage.

Heugens, P. P. M. A. R., \& Lander, M. W. 2009. Structure! Agency! (and other quarrels): A meta-analysis of institutional theories of organization. Academy of Management Journal, 52: 61-85.

Higgins, M. C., \& Gulati, R. 2003. Getting off to a good start: The effects of upper echelon affiliations on underwriter prestige. Organization Science, 14: 244-263.

Hinnings, C. R., \& Tolbert, P. S. 2008. Organizational institutionalism and sociology: A reflection. In R. Greenwood, C. Oliver, K. Sahlin, \& R. Suddaby (Eds.), The sage handbook of organizational institutionalism: 473-490. Los Angeles: Sage.

Hirsch, P. M., \& Lounsbury, M. 1997. Putting the organization back into organization theory. Journal of Management Inquiry, 6: 79-88.

Hoffman, A. J., \& Ventresca, M. J. 2002. Organizations, Policy, and the Natural Environment. Stanford: Stanford University Press. 
Ingram, P., \& Simons, T. 1995. Institutional and resource dependence determinants of responsiveness to work-family issues. The Academy of Management Journal, 38: $1466-1482$.

Kamins, M. A., \& Alpert, F. H. 2004. Corporate claims as innovator or market leader: Impact on overall attitude and quality perceptions and transfer to company brands. Corporate Reputation Review, 7: 147-159.

Kaplan, A. M., \& Haenlein, M. 2010. Users of the world, unite! The challenges and opportunities of social media. Business Horizons, 53: 59-68.

Kaplan, A. M., \& Haenlein, M. 2011. Two hearts in three-quarter time: How to waltz the social media/viral marketing dance. Business Horizons, 54: 253-263.

Katz, E., Levin, M. L., \& Hamilton, H. 1963. Traditions of research on the diffusion of innovation. American Sociological Review, 28: 237-252.

Katz, M. L., \& Shapiro, C. 1987. R and D rivalry with licensing or imitation. The American Economic Review, 77: 402-420.

Kennedy, M. T., \& Fiss, P. C. 2009. Institutionalization, framing, and diffusion: The logic of TQM adoption and implementation decisions among U.S. hospitals. Academy of Management Journal, 52: 897-918.

Kietzmann, J. H., Hermkens, K., McCarthy, I. P., \& Silvestre, B. S. 2011. Social media? Get serious! Understanding the functional building blocks of social media. Business Horizons, 54: 241-251.

Kim, W., Jeong, O. R., \& Lee, S. W. 2010. On social web sites. Information Systems, 35: $215-236$.

King, R. 2007. Business goes straight to video, Bloomberg Businessweek.

Kraatz, M. S., \& Zajac, E. J. 1996. Exploring the limits of the new institutionalism: The causes and consequences of illegitimate organizational change. American Sociological Review, 61: 812-836.

Kumar, A. 2011. Online Business Models for Social Media and their Implementation Using Web 2.0. Unpublished 1503306, University of South Carolina, United States -- South Carolina.

Lawrence, P. R., \& Lorsch, J. W. 1967. Organization and Environment: Managing Differentiation and Integration. Boston, MA: Harvard University.

Lawton, R. B., \& Wholey, D. R. 1993. Adoption and abandonment of matrix management programs: Effects of organizational characteristics and interorganizational networks. The Academy of Management Journal, 36: 106138 . 
Lee, C. 2012. Jony Ive explains some of the secrets to Apple's sauce, iDownloadBlog.

Lee, K., \& Pennings, J. M. 2002. Mimicry and the market: Adoption of a new organizational form. The Academy of Management Journal, 45: 144-162.

Lerman, K., Galstyan, A., Ver Steeg, G., \& Hogg, T. 2011. Stochastic models of social media dynamics: USC information sciences institute.

Levine, S. S., \& Prietula, M. J. 2011. How knowledge transfer impacts performance: A multilevel model of benefits and liabilities. Organization Science.

Lightspeed Research. 2011. Consumers rely on online reviews and price comparisons to make purchase decisions. Retrieved April 9, 2012, from

http://www.lightspeedresearch.com/press-releases/consumers-rely-on-onlinereviews-and-price-comparisons-to-make-purchase-decisions/

LinkedIn. 2011. Social media for the career minded. Retrieved April 9, 2012, from http://www.marketingpilgrim.com/wp-content/uploads/2011/09/Social-MediaFor-the-Career-Minded.png

Losapio, S. 2012. Women-Owned Small Businesses in the Service Industry. Unpublished 3491434, Walden University, United States -- Minnesota.

Lounsbury, M. 2007. A tale of two cities: Competing logics and practice variation in the professionalizing of mutual funds. Academy of Management Journal, 50: 289307.

Love, E. G., \& Cebon, P. 2008. Meanings on multiple levels: The Influence of field-level and organizational-level meaning systems on diffusion. Journal of Management Studies, 45: 239-267.

Maleshefski, T. 2011. Social media and the future of customer support, Zendesk. Retrieved April 9, 2012, from http://www.zendesk.com/blog/social-media-andthe-future-of-customer-support

Mashable. 2011. Figures on social media. Retrieved April 9, 2012, from http://mediabistro.com/alltwitter/files/2011/12/social-media-statistics.jpg

Mediabistro. 2011. The growth of social media. Retrieved April 9, 2012, from http://mediabistro.com/alltwitter/files/2011/08/growth-social-media.jpg

Mediabistro. 2012. Stats of the day. Retrieved April 27, 2012, from http://mediabistro.com/alltwitter/files/2011/12/social-media-statistics.jpg

Meyer, J. W., \& Rowan, B. 1977. Institutionalized organizations: Formal Structure as myth and ceremony. American Journal of Sociology, 83: 340-363. 
Meyer, J. W., \& Rowan, B. 1983. The structure of educational organizations. In J. W. Meyer, \& B. Rowan (Eds.), Organizational Environments: Ritual and Rationality. Beverly Hills, CA: Sage Publications.

Mizruchi, M. S., \& Fein, L. C. 1999. The social construction of organizational knowledge: A study of the uses of coercive, mimetic, and normative isomorphism. Administrative Science Quarterly, 44: 653-683.

Morphy, E. 2012. Luxury brands on social media: All they have to do is show up, Forbes. Retrieved April 27, 2012, from http://www.forbes.com/sites/erikamorphy/2012/10/30/luxury-brands-on-socialmedia-all-they-have-to-do-is-show-up/

Nadkarni, S., \& Barr, P. S. 2008. Environmental context, managerial cognition, and strategic action: an integrated view. Strategic Management Journal, 29(13): 1395-1427.

National Resaurant Association. 2011. 2011 Restaurant industry forecast. Retrieved April 9, 2012, from http://restaurant.org/reports

O'Reilly, T. 2005. What is web 2.0, O'REILLY: Spreading the knowledge of innovators. Retrieved April 9, 2012, from http://oreilly.com/web2/archive/what-is-web20.html

Ocasio, W. 1997. Towards an attention-based view of the firm. Strategic Management Journal, 18(S1): 187-206.

OECD. 2007. Participative web and user-created content: Web 2.0, wikis, and social networking. Paris: Organisation for Economic Co-operation and Development.

Palmer, D., \& Biggert, N. 2002. Organizational institutions. In J. A. Baum (Ed.), Companion to Organizations: 259-280. Oxford: Blackwell.

Pangarkar, N., \& Klein, S. 1998. Bandwagon Pressures and interfirm alliances in the global pharmaceutical industry. Journal of International Marketing, 6: 54-73.

Peddycord, R. 2008. How Obama raised $87 \%$ of his funds through social networking, ResourceNation. Retrieved April 9, 2012, from http://www.resourcenation.com/blog/how-obama-used-social-networking-to-setfundraising-records/

Perrow, C. 1981. Normal accident at Three Mile Island. Society, 18: 17-26.

Pfeffer, J. 1982. Organizational demography. In L. L. Cummings, \& B. M. Staw (Eds.), Research in Organizational Behavior. Greenwich, CT: JAI Press.

Pfeffer, J., \& Salancik, G. R. 1978. The External Control of Organizations: A Resource Dependence Perspective. New York, NY: Harper and Row. 
Porter, M. E. 1980. Competitive Strategy. New York: Free Press.

Powell, W. W. 1991. Expanding the scope of institutional analysis. In W. W. Powell, \& P. J. DiMaggio (Eds.), The new institutionalism in organizational analysis: 183203. Chicago, IL: University of Chicago Press.

Rao, L. 2011. Beyonce pregnancy news at MTV VMAs births new Twitter record of 8,868 tweets per second, TechCrunch. Retrieved April 9, 2012, from http://techcrunch.com/2011/08/29/beyonce-pregnancy-news-at-the-mtv-vmasbirths-new-twitter-record-with-8868-tweets-per-second/

Rayfield, D. 2011. Social media's shocking statistics, HarpSocial. Retrieved April 9, 2012, from http://harpsocial.com/2011/04/social-medias-shocking-statistics/

Reed, F. 2010. Manufacturing cos. don't need social media and the internet?, FrankThinking about internet marketing. Retrieved April 9, 2012, from http://www.frankthinking.com/manufacturing-cos-dont-need-social-media-andthe-internet/

Rindova, V. P., Pollock, T. G., \& Hayward, M. L. A. 2006. Celebrity firms: The social construction of market popularity. Academy of Management Review, 31: 50-71.

Ritchie, W. J., \& Melnyk, S. A. 2012. The impact of emerging institutional norms on adoption timing decisions: Evidence from C-TPAT - a government antiterrorism initiative. Strategic Management Journal, 33: 860-870.

Rodgers, D. J. 2012. The social media dilemma in education: Policy design, implementation and effects. Unpublished Ed.D., University of Southern California, United States -- California.

Ross, L., \& Nisbett, R. E. 1991. The Person and the Situation: Perspectives of Social Psychology. New York: McGraw-Hill.

Sanders, W. G., \& Tuschke, A. 2007. The adoption of institutionally contested organizational practices: The emergence of stock option pay in germany. Academy of Management Journal, 50: 33-56.

Schicker, M. A. 2011. Counselor Perception of Effective Components of Suicide Prevention Programs in Four-Year Colleges and Universities. Unpublished Ed.D., Lindenwood University, United States -- Missouri.

Schneiberg, M., \& Soule, S. A. 2005. Institutionalization as a contested, multilevel process: The case of rate regulation in American fire insurance. In G. Davis, D. McAdam, W. R. Scott, \& M. Zald (Eds.), Social movements and organization theory: 122-160. Cambridge, UK: Cambridge University Press. 
Scott, W. R. 1983. The organization of environments: Network, cultural and historical elements. In J. W. Meyer, \& B. Rowan (Eds.), Organizational Environments: Ritual and Rationality. Beverly Hills, CA: Sage Publications.

Scott, W. R. 1987. The adolescence of institutional theory. Administrative Science Quarterly, 32: 493-511.

Scott, W. R. 1992. Organizations: Rational, Natural, and Open Systems (3rd ed.). Englewood Cliffs, NJ: Prentice-Hall.

Scott, W. R. 1995. Institutions and Organizations (1st ed.). Thousand Oaks, CA: Sage.

Scott, W. R. 2001. Institutions and organizations (2nd ed.). Thousand Oaks, CA: Sage.

Scott, W. R., Ruef, M., Mendel, P. J., \& Caronna, C. A. 2000. Institutional Change and Healthcare Organizations: From Professional Dominance to Managed Care. Chicago, IL: University of Chicago Press.

Sharfman, M. P., Wolf, G., Chase, R. B., \& Tansik, D. A. 1988. Antecedents of organizational slack. The Academy of Management Review, 13: 601-614.

Sherer, P. D., \& Lee, K. 2002. Institutional change in large law firms: A resource dependency and institutional perspective. The Academy of Management Journal, 45: 102-119.

Short, J., Williams, E., \& Christie, B. 1976. The social psychology of telecommunications. Hoboken, NJ: John Wiley \& Sons, Ltd.

Singh, J. V., Tucker, D. J., \& House, R. J. 1986. Organizational legitimacy and the liability of newness. Administrative Science Quarterly, 31: 171-193.

Socialmedia.org. 2009. My Starbucks idea generates 70,000 ideas in its first year, The Big List Blog. Retrieved April 9, 2012, from http://www.socialmedia.org/blog/case-studies/my-starbucks-idea-generates70000-ideas-in-its-first-year

Starbucks. 2012. My Starbucks Idea. Retrieved April 9, 2012, from http://mystarbucksidea.force.com/apex/ideafaq

Steel, E. 2012. 'Kony 2012' sets mark as fastest-spreading viral video, The Wall Street Journal. Retrieved April 9, 2012, from http://blogs.wsj.com/digits/2012/03/09/kony-2012-sets-mark-as-fastest-spreadingviral-video/

Stirratt, A. A. 2011. Social media use in March 2011 Japanese Crisis: Impact on emergency preparedness advocacy. Unpublished M.P.H., Purdue University, United States -- Indiana. 
Suchman, M. C. 1995. Managing legitimacy: Strategic and institutional approaches. The Academy of Management Review, 20: 571-610.

Teece, D. J. 1980. The diffusion of an administrative innovation. Management Science, 26: 464-470.

Thornton, P. H. 2004. Markets from culture: Institutional logics and organizational decisions in higher education publishing. Stanford, CA: Stanford University Press.

Tolbert, P. S., \& Zucker, L. G. 1983. Institutional sources of change in the formal structure of organizations: The diffusion of civil service reform, 1880-1935. Administrative Science Quarterly, 28: 22-39.

Twitter. 2012. About Twitter. Retrieved April 30, 2012, from https://twitter.com/about

Usita, L. 2011. Adolescent identity formation in online space. Unpublished Ed.D., Talbot School of Theology, Biola University, United States -- California.

Vargo, S. L., \& Lusch, R. F. 2004. Evolving to a new dominant logic for marketing. Journal of Marketing, 68: 1-17.

Vergeer, M., \& Pelzer, B. 2009. Consequences of media and Internet use for offline and online network capital and well-being. A causal model approach. Journal of Computer-Mediated Communication, 15: 189-210.

Verni, R. 2012. Facebook: Shifting privacy, identity, and power online. Unpublished Ph.D., City University of New York, United States -- New York.

Westphal, J. D., Gulati, R., \& Shortell, S. M. 1997. Customization or conformity? An institutional and network perspective on the content and consequences of TQM adoption. Administrative Science Quarterly, 42: 366-394.

Westphal, J. D., \& Zajac, E. J. 1994. Substance and symbolism in CEOs' long-term incentive plans. Administrative Science Quarterly, 39: 367-390.

YouTube. 2012a. Charts. Retrieved July 14, 2012, from http://www.youtube.com/charts/videos_views?t=a

YouTube. 2012b. Statistics. Retrieved April 27, 2012, from http://www.youtube.com/t/press_statistics

YouTube. 2012c. Will It blend?. Retrieved July 14, 2012, from http://www.youtube.com/user/Blendtec

Zimmerman, M. A., \& Zeitz, G. J. 2002. Beyond survival: Achieving new venture growth by building legitimacy. The Academy of Management Review, 27: 414431. 
Zucker, L. G. 1983. Organizations as institutions. Research in the Sociology of Organizations: 1-47.

Zucker, L. G. 1987. Institutional theories of organization. Annual Review of Sociology, 13: 443-464.

Zuckerberg, R. 2011. Status update. Retrieved April 9, 2012, from https://twitter.com/randizuckerberg/status/22187407218577408 


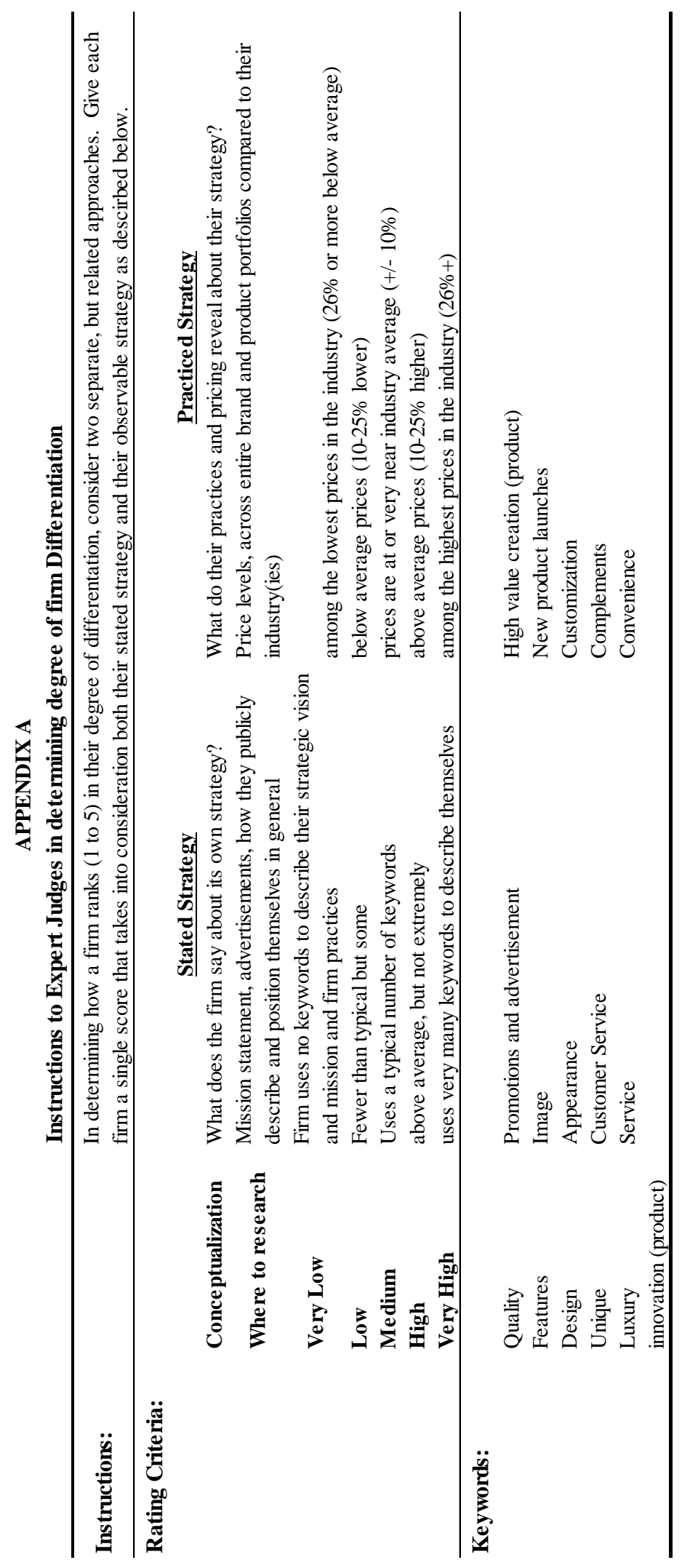




\section{VITA}

Brent Clark earned his BS in Statistics with an emphasis in Actuarial Science from

Brigham Young University in 2004. He then spent three years working as an Actuarial Analyst for Lincoln Financial Group in Fort Wayne, Indiana. After this, he returned to Brigham Young University and earned his MBA with a dual emphasis in Finance and Program Management in 2008. Brent then spent a year and a half working in the Aerospace Industry at Alliant

Techsystems Inc. as a program analyst before returning to school to study Management in the PhD program in the Trulaske College of Business at the University of Missouri.

He is a member of the Academy of Management and the Strategic Management Society. He has taught the Strategic Management Capstone course for the last four years. His research has been presented at national and international conferences and he serves as a reviewer for Strategic Management Journal. He has accepted a tenure track position as Assistant Professor of Management at the University of South Dakota to begin in August of 2013. 